\title{
Post-intervention analysis of pre-eclampsia and eclampsia in three Nigerian states
}

Salisu Mohammed Ishaku

Emmanuel Nwala

Gloria Adoyi

Charles Nwigwe

Solomon Kongyamba

See next page for additional authors

Follow this and additional works at: https://knowledgecommons.popcouncil.org/departments_sbsr-rh

Part of the Demography, Population, and Ecology Commons, Family, Life Course, and Society Commons, Gender and Sexuality Commons, International Public Health Commons, Maternal and Child Health Commons, Medicine and Health Commons, and the Women's Health Commons How does access to this work benefit you? Let us know!

\section{Recommended Citation}

Ishaku, Salisu Mohammed, Emmanuel Nwala, Gloria Adoyi, Charles Nwigwe, Solomon Kongyamba, Udochisom Anaba, Caroline Johnson, Karen Kirk, Pooja Sripad, and Charlotte E. Warren. 2019. "Postintervention analysis of pre-eclampsia and eclampsia in three Nigerian states," Ending Eclampsia Landscape Endline Report. Washington, DC: Population Council. 


\section{Authors}

Salisu Mohammed Ishaku, Emmanuel Nwala, Gloria Adoyi, Charles Nwigwe, Solomon Kongyamba, Udochisom Anaba, Caroline Johnson, Karen Kirk, Pooja Sripad, and Charlotte E. Warren 


\section{ENDING Eclampsia}

POST-INTERVENTION ANALYSIS OF PRE-ECLAMPSIA AND ECLAMPSIA IN THREE NIGERIAN STATES

Salisu Ishaku, Emmanuel Nwala, Gloria Adoyi, Charles Nwigwe, Solomon Kongyamba, Udochism Anaba, Caroline Johnson, Karen Kirk, Pooja Sripad, Charlotte Warren

April 2019 


\section{ENDING}

Ending Eclampsia seeks to expand access to proven, under-utilized interventions and commodities for the prevention, early detection, and treatment of pre-eclampsia and eclampsia and strengthen global partnerships.

\section{POPUlation COUNCIL \\ Ideas. Evidence. Impact.}

The Population Council confronts critical health and development issues-from stopping the spread of HIV to improving reproductive health and ensuring that young people lead full and productive lives. Through biomedical, social science, and public health research in 50 countries, we work with our partners to deliver solutions that lead to more effective policies, programs, and technologies that improve lives around the world. Established in 1952 and headquartered in New York, the Council is a non-governmental, non-profit organization governed by an international board of trustees.

\section{Population Council}

4301 Connecticut Avenue NW, 280

Washington DC, 20008

Tel: +1. 877.237.9400

www.popcouncil.org

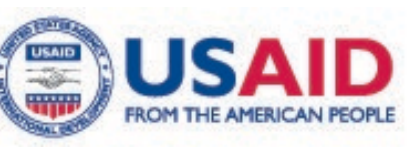

The Ending Eclampsia project is made possible by the generous support of the American people through the United States Agency for International Development (USAID) under the terms of USAID APS-OAA-14-000048. The contents of this report are the sole responsibility of the Ending Eclampsia project and the Population Council and do not necessarily reflect the views of USAID or the United States Government. 


\section{Table of Contents}

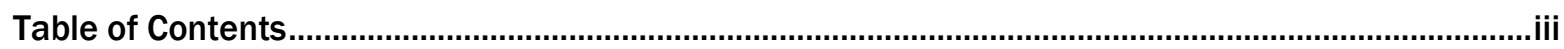

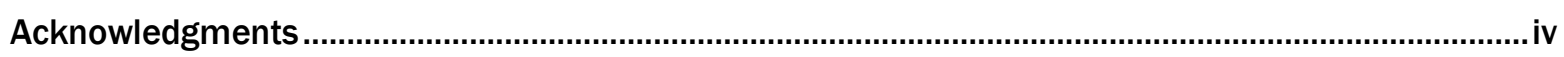

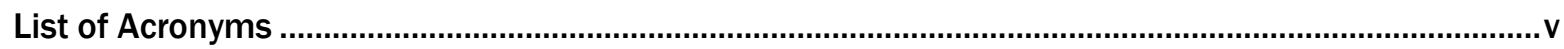

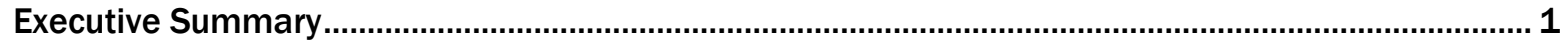

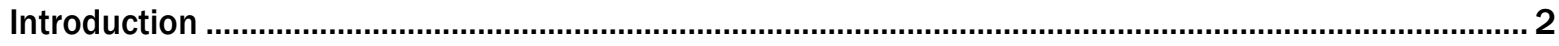

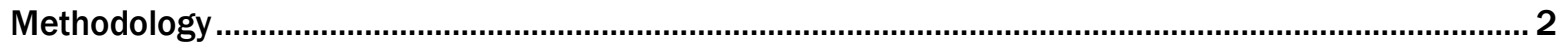



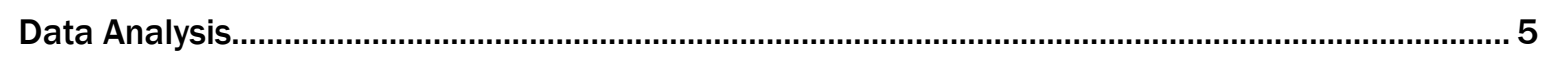

Ethical Review and Consent Process ......................................................................................... 5

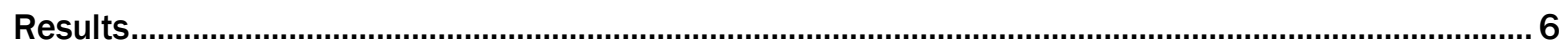

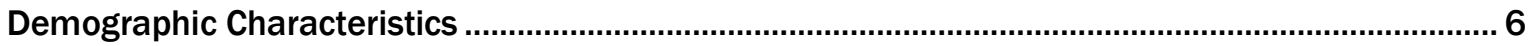

Policy Environment and Stakeholder Support for PE/E Improvement .......................................... 9

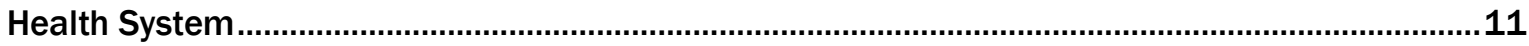

Community Perceptions and Understanding of PE/E...................................................................19

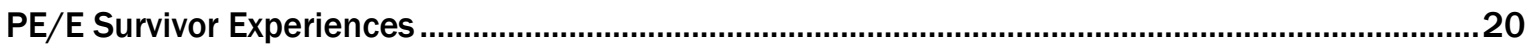








\section{Acknowledgments}

The Ending Eclampsia Project conducted a baseline landscape analysis in 2015 followed by interventions to scale up underutilized interventions and commodities to improve access to early detection and treatment of preeclampsia and eclampsia. This report presents a repeat landscape analysis describing changes in prevention, detection, management and referral of pre-eclampsia and eclampsia. We are grateful for all those who provided programmatic and facility-based support to the scale up activities, including the Federal and state ministries of Health in Cross River, Ebonyi, and Kogi states and the USAID Mission Office in Nigeria.

We acknowledge professional associations, implementing partners, and individual USAID colleagues (Joseph Monehin, Alaa El-Bashir, Emily Hillman, and Deborah Armbruster) who provided valuable inputs during project implementation and dissemination. The successful completion of the study would not have been possible without the dedication of service providers in the participating health facilities. We thank all the study participants, who gave their time and provided valuable information during the course of the study. 


\section{List of Acronyms}

\begin{tabular}{|c|c|}
\hline ANC & Antenatal care \\
\hline BP & Blood pressure \\
\hline CHEW & Community health extension worker \\
\hline $\mathrm{CHO}$ & Community Health Officer \\
\hline CS & Caesarean section \\
\hline EmONC & Emergency Obstetric and Neonatal Care \\
\hline FGD & Focus group discussion \\
\hline FMoH & Federal Ministry of Health \\
\hline FP & Family Planning \\
\hline GA & Gestational Age \\
\hline HDP & Hypertensive disorder of pregnancy \\
\hline IDI & In-depth interview \\
\hline IM & Intramuscular \\
\hline IV & Intravenous \\
\hline $\mathrm{MgSO}_{4}$ & Magnesium sulphate \\
\hline MoH & Ministry of Health \\
\hline $\mathrm{PE} / \mathrm{E}$ & Pre-eclampsia and eclampsia \\
\hline PHC & Primary health care \\
\hline PPH & Post-partum hemorrhage \\
\hline $\mathrm{RH}$ & Reproductive Health \\
\hline SD & Standard Deviation \\
\hline TBA & Traditional birth attendant \\
\hline UNFPA & United Nations Population Fund \\
\hline UNICEF & United Nations Children's Fund \\
\hline USAID & United States Agency for International Development \\
\hline WHO & World Health Organization \\
\hline
\end{tabular}




\section{Executive Summary}

In the last three decades, global maternal mortality has decreased by almost 45 percent. Despite this overall improvement, approximately 830 women still die every day from largely preventable pregnancy complications, and sub-Saharan Africa alone accounts for over 66 percent of global maternal deaths. The majority of Nigeria's more than 58,000 maternal deaths in 2015 were caused by pre-eclampsia, eclampsia, or postpartum hemorrhage. Pre-eclampsia and eclampsia are now the leading direct causes of maternal mortality in Nigeria and, with postpartum hemorrhage, account for more than one third of severe maternal outcomes (23.4\% and $14.4 \%$, respectively).

In response, in 2015 the Ending Eclampsia project analyzed the country's six geo-political zones' (covering seven states) primary and secondary health care facilities' preparedness for response to the needs of pregnant women with pre-eclampsia and eclampsia. The project then introduced a primary health care model to enhance both the capacities and service quality of 180 facilities to address pre-eclampsia and eclampsia in three of the seven states surveyed-Cross River, Ebonyi, and Kogi. This report describes the post-intervention evaluation.

Primary and secondary health care providers' knowledge and practice improved: Notably, community health extension workers who provide primary care, if trained and mentored, can effectively detect pre-eclampsia early, and manage it with a loading dose of magnesium sulphate (when indicated) preceding referrals. In addition, all stakeholders involved in the evaluation support full implementation of the national revised task shifting policy permitting primary care providers (community health extension workers and health officers) to detect and provide loading doses of magnesium sulphate to women with severe pre-eclampsia and eclampsia. Primary and secondary health care providers have shown promise in their ability to diagnose and classified sub-sets of hypertensive disorders in pregnancy. This is important because specific care pathway for each sub-type varies.

Training logistics officers specifically on commodity logistics and supplies resulted in fewer stock outs at facilities. More efforts are required, however, for sustaining policy-maker advocacy for improved human resources management in addition to a regular and responsive maternal health commodity management system. International and local guidelines for managing hypertensive disorders in pregnancy are not generally available sub-nationally, and where available, providers are not trained to use them properly, resulting in missed opportunities for arresting hypertensive development. Future efforts should focus on eliminating these gaps.

This evaluation's results also show that empowered pregnant women request quality maternal health services (during antenatal visits) and ask questions about their health and those of their unborn infants. Trained personnel with essential commodities and tools will not result in significant progress if pregnant women do not register themselves early in the first trimester for antenatal care, when pre-eclampsia is amenable to preventive measures such as prophylaxis aspirin. 


\section{Introduction}

In the last three decades, global maternal mortality has decreased by almost 45 percent, but approximately 830 women still die daily from largely preventable pregnancy complications (World Health Organization 2018, World Health Organization, UNICEF, UNFPA, World Bank Group, United Nations Population Division 2015). Despite this overall improvement, low- and middle income countries continue to bear 99 percent of the burden of maternal deaths, with sub-Saharan Africa alone accounting for over 66 percent of global maternal deaths (World Health Organization et al. 2015). The majority of Nigeria's more than 58,000 maternal deaths in 2015 were caused by pre-eclampsia and eclampsia (PE/E) and postpartum hemorrhage (PPH) (Oladapo et al. 2015, World Health Organization et al. 2015). PE/E is now the leading direct cause of maternal mortality in Nigeria and, with PPH, accounts for more than one third of severe maternal outcomes (23.4\% and 14.4\%, respectively, Oladapo et al. 2015).

Since 2015, the Ending Eclampsia project, with support from USAID, has been working to expand proven, under-utilized interventions and commodities for PE/E prevention, early detection, and treatment, and to strengthen global partnerships and networks for care of hypertensive disorders in pregnancy (HDPs), of which PE/E are the severest forms. A systematic review of the literature (the report of which can be found at endingeclampsia.org) by the project identifies a number of articles reporting PE/E burdens within set populations, common risk factors, adverse outcomes, and mortality rates, but few discuss implementation research (IR) to improve PE/E prevention, detection, and timely management.

Following the literature review and subsequent analysis of antenatal care (ANC) and PE/E in seven Nigerian states in 2015, the Ending Eclampsia project began to intensify its activities and IR in Cross River, Ebonyi, and Kogi states, emphasizing task sharing with primary health care (PHC) providers for the detection and management of HDP including PE/E. (For more information on the baseline data report, described as a landscape analysis, please visit www.endingeclampsia.org.)

This report describes the IR approach of the Population Council in Nigeria from 2016 to 2018 and its results, specifically changes in a range of areas including:

- Policy and programmatic support for PE/E detection and treatment

- PHC providers' capacities to identify and manage PE/E

- $\mathrm{PHC}$ provider's knowledge and competence in preventing, detecting, and managing PE/E, and

- Communities' PE/E awareness, beliefs, and experiences.

\section{Methodology}

The project analyzed the contexts of PE/E awareness and treatment in PHC and secondary health facilities selected for the PE/E intervention in Ebonyi, Cross River, and Kogi states, before and after the intervention, in collaboration with the Federal Ministry of Health (FMoH) and USAID. This pre-post, cross-sectional design integrated qualitative and quantitative data collected at both baseline (2015) and endline (2018).

Researchers assessed facility readiness and capacities to identify, treat, and manage PE/E at PHC and secondary health care levels. The Ending Eclampsia team conducted facility assessments, interviewed laboratory staff and care providers who work in ANC, maternity, and labor and delivery wards, observed client and provider interactions during ANC consultations, and interviewed pregnant women leaving assessed facilities, where the women had received ANC services (i.e. exit interviews). All facilities surveyed at baseline were also evaluated at endline. 
The project collected data at PHC and secondary facilities from women detected with pre-eclampsia who received treatment, and followed them until delivery to determine their maternal and fetal outcomes. Survivors of PE/E were also interviewed to understand their individual routes of care before they received successful maternity services. Women (18 to 49 years of age) and men (ages 18 to 55) from the local communities also participated in focus group discussions (FGDs) for an understanding of their knowledge and perceptions of maternal complications including PE/E, and typical routes of care. Data collection also included in-depth interviews (IDIs) with national, state and local government areas (LGA) policy-makers.

TABLE 1 Data Collection tools at baseline and endline

\begin{tabular}{|c|c|c|c|c|c|c|c|c|}
\hline \multicolumn{9}{|l|}{ Core Intervention } \\
\hline \multirow{2}{*}{ Data collection tools } & \multicolumn{2}{|c|}{ Cross River } & \multicolumn{2}{|c|}{ Ebonyi } & \multicolumn{2}{|c|}{ Kogi } & \multicolumn{2}{|c|}{ Total } \\
\hline & Baseline & Endline & Baseline & Endline & Baseline & Endline & Baseline & Endline \\
\hline Health facility assessments & 11 & 54 & 20 & 57 & 8 & 60 & 39 & 171 \\
\hline FGDs with men \& women & 4 & 4 & 4 & 4 & 4 & 4 & 12 & 12 \\
\hline IDIs with laboratory staff & 4 & 6 & 5 & 6 & 0 & 6 & 9 & 18 \\
\hline IDls with PE/E survivors & 5 & 6 & 5 & 6 & 5 & 6 & 15 & 18 \\
\hline IDls with policymakers & 10 & 18 & 10 & 18 & 10 & 28 & 30 & 64 \\
\hline Observations of ANC visits & 15 & 240 & 10 & 119 & 15 & 266 & 40 & 625 \\
\hline Exit interviews with ANC women & 15 & 240 & 10 & 119 & 15 & 266 & 40 & 625 \\
\hline Interviews with PHC providers & 59 & 74 & 46 & 89 & 74 & 73 & 149 & 236 \\
\hline IDIs with store manager & - & 11 & - & 11 & - & 13 & - & 35 \\
\hline Monitoring data & \multicolumn{2}{|c|}{81} & \multicolumn{2}{|c|}{55} & \multicolumn{2}{|c|}{40} & \multicolumn{2}{|c|}{176} \\
\hline
\end{tabular}

Three subsidiary IR studies (detailed in separate reports) assessed the feasibility shifting anti-hypertensive drug (alpha-methyl dopa) provision to PHC facilities (in Ebonyi and Kogi), the utilization of women's groups platforms to increase community PE/E awareness and use of quality essential maternal and child health services (in Cross River), and in seven states-Bauchi, Cross River, Ebonyi, Kano, Kogi, Ondo, and Sokotoconducted a hospital-based postpartum follow up study of cohort women and their infants (up to one year after delivery) whose pregnancies were complicated by HDPs.

\section{Intervention}

This study's primary intervention trained PHC workers, including community health extension workers (CHEWs) and nurses/midwives, and provided them with ongoing mentorship, to identify the signs of preeclampsia, administer $\mathrm{MgSO}_{4}$, and refer pregnant women to secondary facilities for continued PE/E management. After the initial baseline (pre-intervention) analysis, 180 facilities ( 36 secondary facilities and $144 \mathrm{PHC}$ facilities) were purposively selected in three states to participate in the intervention, following discussions with each state's ministry of Health $(\mathrm{MoH})$.

In conjunction with each state $\mathrm{MoH}$, health care providers were selected for refresher training in PE/E management. In every secondary facility included, seven care providers were selected (two ANC nurses, two maternity/labor ward nurses, a medical officer, laboratory scientist, and hospital pharmacist). At each PHC facility, two CHEWs or community health officers (CHOs) were selected. Each facility received service provision manuals, job aids, seed stocks of $\mathrm{MgSO}_{4}$.

The project and state MoHs conducted mentorship and supervisory visits throughout the intervention, strengthening each hospital's central store commodities logistics capacity. Direct intervention activities varied in each state: 24 months in Ebonyi, 18 months in Cross River, and 14 months in Kogi. (The two subsidiary IR studies in Ebonyi and Cross River, as well as the postpartum follow up studies, are also shown as promising practices tested in Figure 1 on the following page but are reported elsewhere.) 
Figure 1: Primary Health Care PE/E Model

\section{PRIMARY HEALTHCARE PE/E MODEL}

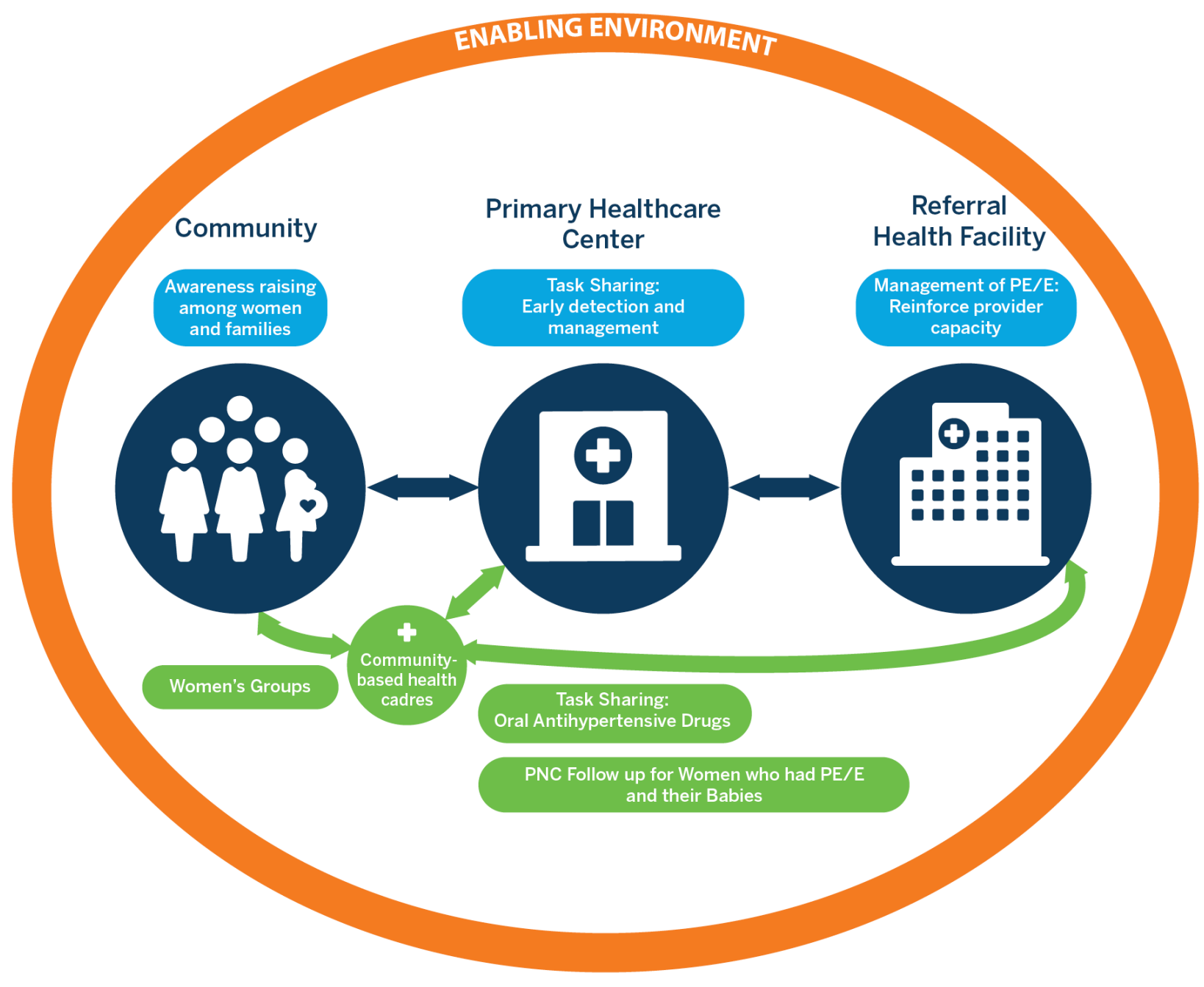

Promising practices from PE/E research

- Women's groups improve PE/E awareness within $\mathrm{PE} / \mathrm{E}$ awareness within
communities and provide health education on importance of early antenatal care (ANC).

- Task-sharing early detection and management to other community-based health cadres in context (e.g. community midwives)

- Oral antihypertensive drugs are a key component of task shifting detection and management of PE/E to primary healthcare centers (PHC), strengthening the quality of ANC and postnatal care (PNC).

- PNC follow up for women who had PE/E should occur at all levels of the health system.

\begin{tabular}{|l|}
\hline \multicolumn{1}{|c|}{ Legend } \\
Essential PE/E activities \\
Other promising practices \\
Enabling Environment: \\
National policy \& standardized clinical \\
protocols, stakeholder engagement, \\
funding, infrastructure, human \\
resources, supply chain for essential \\
drugs and commodities \\
Client referral
\end{tabular}




\section{Data Analysis}

Completed questionnaires were transferred to Population Council's office in Abuja for data entry and analysis. Quantitative data analysis, including descriptive, bivariate, and comparative statistics (chisquared and Fisher's Exact tests), used SPSS and STATA; chi-squared tests with more than two levels were analyzed using a web platform, Social Science Statistics (www.socscistatistics.com, Kim 2017). In some cases, summary scores were generated in STATA to assess multi-component constructs such "Assessing risk for $\mathrm{PE} / \mathrm{E}$ ".

Qualitative interviews were digitally recorded, supported by field notes, then transcribed and translated into English. Content analysis used NVivo software, applying a grounded theory approach at baseline, drawing inductively from stakeholder perspectives; at endline, thematic coding applied this codebook to endline data, allowing for comparisons over time. Use of multiple methods and perspectives enabled triangulation, particularly between observed ANC visits, provider descriptions, and women's reported experience of care. Findings are reported at policy, health system, and community levels.

Figure 2: Study Reporting Process

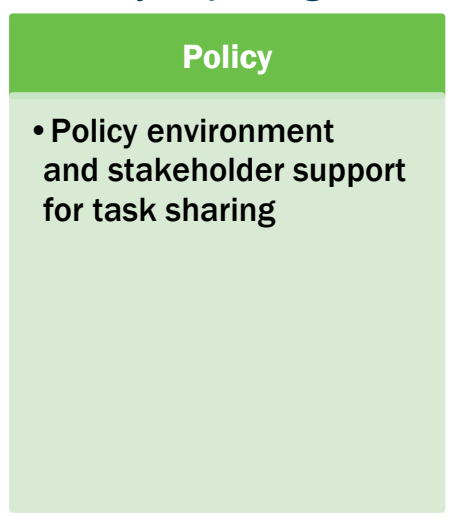

Health System
- Provider knowledge
of PE/E prevention
and detection
- Provider practices
for PE/E prevention
and management
- Commodity and supply
chain for emergency
management of HDPs

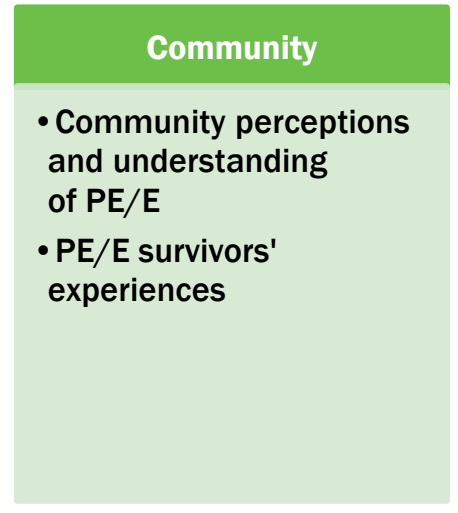

\section{Ethical Review and Consent Process}

Study protocols for the landscape study of Cross River, Ebonyi, and Kogi were reviewed and approved by the Population Council's Institutional Review Board (IRB) in New York, with additional reviews and approvals by the National Health Research Ethics Committee of the Federal Ministry of Health (FMoH) and the ethics committees of each state's $\mathrm{MoH}$. All participants provided informed consent prior to interviews. Before the study commenced in 2015, the Council's research team visited $\mathrm{FMoH}$ and state $\mathrm{MoH}$ authorities for administrative approval, investment, and participation in the study.

Figure 3 States included in study at baseline and endline






\section{Results}

\section{Demographic Characteristics}

A total of 385 health care providers were sampled in the three states, with a slight increase in the number of providers sampled at endline. Surveyed providers' ages ranged from 20 to 59 years, with an average age at baseline and endline of 40 (SD 9.5) and 43 (SD 8.3) respectively. Table 2 (following page) lists the characteristics of providers interviewed at baseline and endline.

While doctors, nurses/midwives, and CHEWs were all interviewed, CHEWs comprised the largest number of health care providers in the combined baseline and endline sample. A majority of care providers interviewed were females who had been in their current health care provision roles between one and five years.

Observed differences in provider socio-demographics between baseline and endline (see Table 2, page 7) could be a result of the slight sample size differences as well as the non-randomized nature of the study, which is prone to selection bias.

Over 80 percent of pregnant women interviewed were between the ages of 20 and 39, with teenage pregnancy rate of less than seven percent. Table 3 (on page 8) provides the characteristics of women who participated in the exit interviews at baseline and endline.

Women who participated in interviews were predominantly married or co-habitating (over 90\%). Most interviewed women are educated, with a secondary or tertiary education (about 80\%).

At endline in Cross River and Ebonyi states, 99 percent of women identified as Christian, whereas in Kogi 42 percent identified as Christian and 57 percent identified as Muslim (one woman identified as traditional or no religion). A mixed religious population in Kogi is to be expected, given its central location between the predominantly Muslim north and largely Christian south. 
TABLE 2 Provider Characteristics

\begin{tabular}{|c|c|c|c|c|c|c|c|c|c|c|c|c|}
\hline \multirow{3}{*}{ Characteristics } & \multicolumn{3}{|c|}{$\begin{array}{c}\text { Cross River } \\
(n=133)\end{array}$} & \multicolumn{3}{|c|}{$\begin{array}{c}\text { Ebonyi } \\
(\mathrm{n}=135)\end{array}$} & \multicolumn{3}{|c|}{$\begin{array}{c}\text { Kogi } \\
(n=117)\end{array}$} & \multicolumn{3}{|c|}{$\begin{array}{c}\text { Total } \\
(\mathrm{n}=385)\end{array}$} \\
\hline & $\begin{array}{c}\text { Baseline } \\
(n=59)\end{array}$ & $\begin{array}{l}\text { Endline } \\
(n=74)\end{array}$ & P-value & $\begin{array}{c}\text { Baseline } \\
(n=46)\end{array}$ & $\begin{array}{l}\text { Endline } \\
(n=89)\end{array}$ & & $\begin{array}{c}\text { Baseline } \\
(n=44)\end{array}$ & $\begin{array}{l}\text { Endline } \\
(n=73)\end{array}$ & & $\begin{array}{l}\text { Baseline } \\
(n=149)\end{array}$ & $\begin{array}{l}\text { Endline } \\
(n=236)\end{array}$ & \\
\hline & n (\%) & n (\%) & & n (\%) & n (\%) & P-value & n (\%) & n (\%) & P-value & n (\%) & n (\%) & P-value \\
\hline $\begin{array}{r}\text { Male } \\
\text { Female }\end{array}$ & $\begin{array}{l}11(19.0) \\
48(81.0)\end{array}$ & $\begin{array}{l}10(14.0) \\
64(86.0)\end{array}$ & 0.4 & $\begin{array}{c}8(17.0) \\
38(83.0)\end{array}$ & $\begin{array}{l}13(15.0) \\
76(85.0)\end{array}$ & 0.7 & $\begin{array}{c}4(9.0) \\
40(91.0)\end{array}$ & $\begin{array}{l}11(15.0) \\
62(85.0)\end{array}$ & $0.40^{\wedge}$ & $\begin{array}{c}23(15.4) \\
126(84.6)\end{array}$ & $\begin{array}{c}34(14.4) \\
202(85.6)\end{array}$ & 0.8 \\
\hline $\begin{array}{r}20-29 \\
30-39 \\
40-49 \\
50-59 \\
\text { Missing } \\
\end{array}$ & $\begin{array}{c}6(10.3) \\
21(36.2) \\
22(38.0) \\
9(15.5) \\
1 \\
\end{array}$ & $\begin{array}{c}4(6.6) \\
22(36.7) \\
21(35.0) \\
13(21.7) \\
14 \\
\end{array}$ & 0.8 & $\begin{array}{c}7(16.0) \\
15(34.0) \\
14(31.8) \\
8(18.2) \\
2 \\
\end{array}$ & $\begin{array}{c}5(6.1) \\
27(33.0) \\
28(34.1) \\
22(26.8) \\
7 \\
\end{array}$ & 0.3 & $\begin{array}{c}6(14.3) \\
6(14.3) \\
7(16.7) \\
23(54.7) \\
2 \\
\end{array}$ & $\begin{array}{c}2(3.8) \\
9(17.3) \\
25(34.2) \\
16(30.7) \\
21 \\
\end{array}$ & 0.004 & $\begin{array}{c}19(13.2) \\
42(29.2) \\
43(29.9) \\
40(27.7) \\
5 \\
\end{array}$ & $\begin{array}{c}11(5.7) \\
58(29.9) \\
74(38.1) \\
51(26.3) \\
42 \\
\end{array}$ & 0.07 \\
\hline $\begin{array}{r}<=\text { Primary } \\
>=\text { Secondary }\end{array}$ & $\begin{array}{l}34(58.0) \\
25(42.0) \\
\end{array}$ & $\begin{array}{l}56(76.0) \\
18(24.0) \\
\end{array}$ & 0.03 & $\begin{array}{l}22(48.0) \\
24(52.0) \\
\end{array}$ & $\begin{array}{l}62(70.0) \\
27(30.0) \\
\end{array}$ & 0.01 & $\begin{array}{c}7(15.9) \\
37(84.1)\end{array}$ & $\begin{array}{l}56(77.0) \\
17(23.0) \\
\end{array}$ & $<0.001$ & $\begin{array}{l}63(42.3) \\
86(57.7) \\
\end{array}$ & $\begin{array}{c}174(73.7) \\
62(26.3)\end{array}$ & $<0.001$ \\
\hline $\begin{array}{r}\text { Type of Provider } \quad \text { Doctor } \\
\text { Nurse/Midwife } \\
\text { CHEW/ Others } \dagger\end{array}$ & $\begin{array}{c}9(15.2) \\
25(42.4) \\
25(42.4)\end{array}$ & $\begin{array}{c}1(1.4) \\
25(33.8) \\
48(64.8)\end{array}$ & $\begin{array}{l}0.005^{\wedge} \\
0.3 \\
0.01\end{array}$ & $\begin{array}{c}8(17.4) \\
13(28.3) \\
25(54.3)\end{array}$ & $\begin{array}{c}6(6.7) \\
27(30.3) \\
56(63.0)\end{array}$ & $\begin{array}{c}0.05 \\
0.8 \\
0.3\end{array}$ & $\begin{array}{c}4(9.1) \\
33(75.0) \\
7(15.9)\end{array}$ & $\begin{array}{c}0(0.0) \\
26(35.6) \\
47(64.4)\end{array}$ & $\begin{array}{c}0.02^{\wedge} \\
<0.001 \\
<0.001\end{array}$ & $\begin{array}{l}21(14.1) \\
71(47.7) \\
57(38.2)\end{array}$ & $\begin{array}{c}7(3.0) \\
78(33.1) \\
151(63.9)\end{array}$ & $\begin{array}{c}<0.001 \\
0.004 \\
<0.001\end{array}$ \\
\hline $\begin{array}{rr}\text { Years worked in Unit } & <1 \\
1-5 \\
>5 \\
\text { Missing }\end{array}$ & $\begin{array}{c}19(36.4) \\
25(45.4) \\
10(18.2) \\
5\end{array}$ & $\begin{array}{c}9(12.0) \\
38(51.0) \\
27(37.0) \\
0\end{array}$ & 0.004 & $\begin{array}{c}9(20.5) \\
22(50.0) \\
13(29.5) \\
2\end{array}$ & $\begin{array}{c}38(43.7) \\
24(27.6) \\
25(28.7) \\
2\end{array}$ & 0.02 & $\begin{array}{c}5(14.2) \\
15(42.9) \\
15(42.9) \\
9\end{array}$ & $\begin{array}{c}5(7.0) \\
29(40.3) \\
38(52.7) \\
1\end{array}$ & 0.4 & $\begin{array}{c}33(24.8) \\
62(46.6 \\
38(28.6) \\
16\end{array}$ & $\begin{array}{c}52(22.3) \\
91(39.1) \\
60(38.6) \\
3\end{array}$ & 0.1 \\
\hline
\end{tabular}

$\mathrm{P}<0.05$ is considered statistically significant

^Fisher's Exact Test

Significant results in bold

†Includes paramedic 
TABLE 3 ANC Client Demographic Characteristics

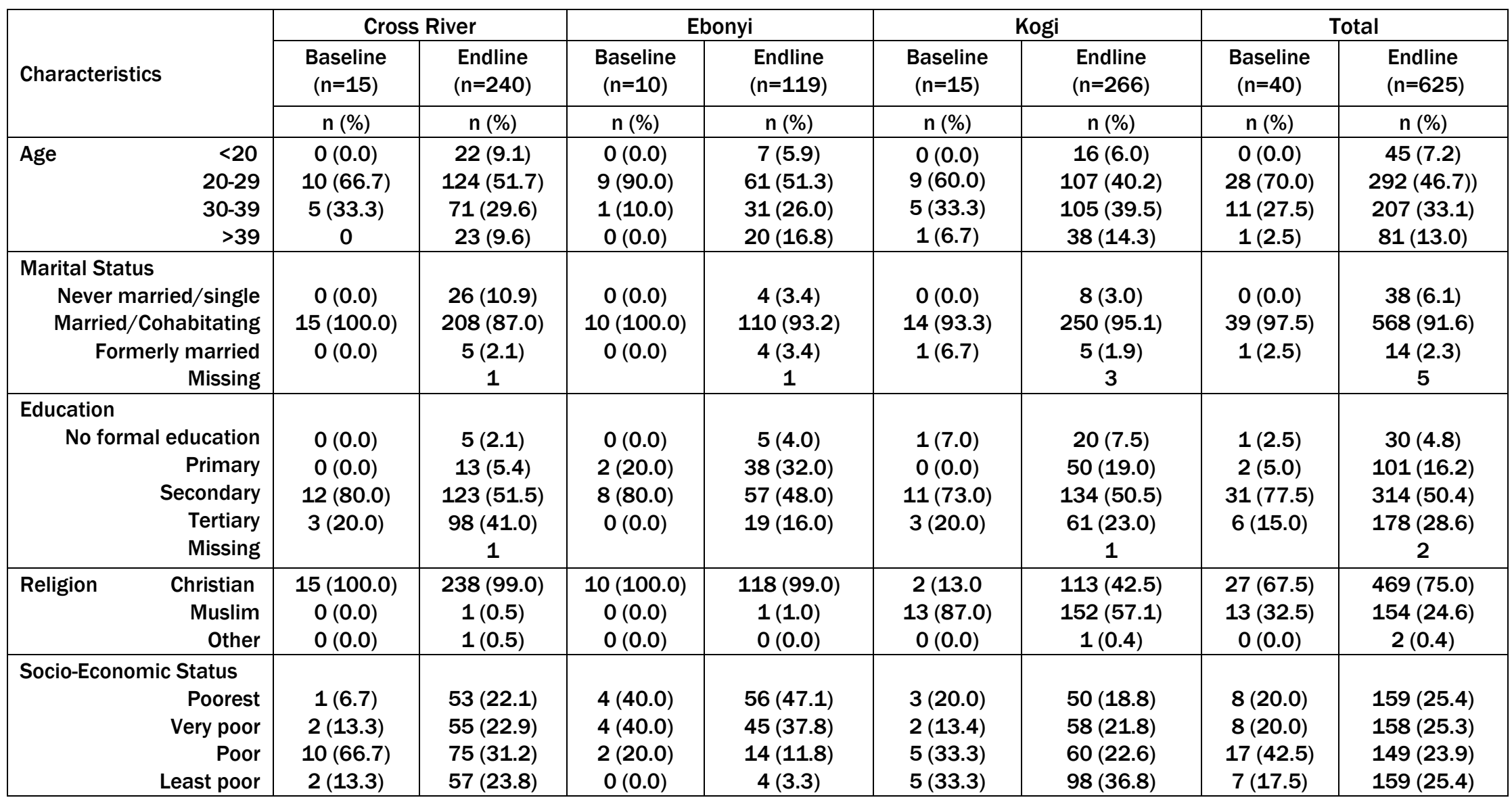

SES, Socio-Economic Status 


\section{Policy Environment and Stakeholder Support for PE/E Improvement}

Policy-makers in Cross River, Ebonyi, and Kogi understand that women in their communities face a range of maternal health challenges. Stakeholders-from the LGA to national level-support strengthening access and use of under-utilized services, especially ANC services, to reduce their communities' PE/E burdens. Following the baseline survey in 2015, policy-makers acknowledge the importance of early ANC registration, lending important political support to the goal of improving maternal health outcomes in pregnancies complicated by $\mathrm{PE} / \mathrm{E}$.

"The question is about going for antenatal [care] early enough at six weeks, at eight weeks, isn't it? This is what we are preaching about pregnancy and management of pregnancy [nowadays]".

Policy-maker, Kogi, 2015

Policy-makers understand that low ANC utilization is often related to structural and other barriers, including poverty, transportation and health care costs, and lack of education, or awareness.

"During first registration they come in enough [in large numbers] but [for] subsequent visits, most of them don't come back...that is one of our greatest challenges."

LGA health manager, Cross River State, 2018

"Poverty is the predominant problem that we have, and other problems we have are illiteracy...and ignorance. Now, these three problems have gone a long way to affect a lot of pregnant women; for instance, because of illiteracy some of them don't know that it is important to attend antenatal care and because of poverty even those who know that it is important to attend antenatal care may not have the money to attend antenatal care. Even those of them that attend [ANC], because of poverty, they may not have the money to do the basic lab investigations that the doctor or the health worker has prescribed. That has gone a long way to affect the maternal morbidity and mortality."

State policy-maker, Ebonyi, 2018

In at least one state, there is evidence that local policy stakeholders are not aware of the latest WHO recommendations for number of ANC contacts for a healthy pregnancy, which increased from four to eight (WHO 2016). As local leaders are charged with ensuring women within their LGAs receive adequate and timely care, mis-information represents a barrier to women's health care needs, and may reflect information disparities between national and lower government levels. Additional information disparities were seen in endline interviews, with policy-makers offering mixed and conflicting information about Nigeria's national protocol for PE/E management: Some were aware of the policy, others were not-yet all showed interest and support for rapid dissemination and implementation of existing policies. Even among state policy-makers familiar with the national PE/E protocol, knowledge of its implementation within local communities was sparse. Knowledge of the policy's implementation was particularly low in Kogi, with most local and state policy-makers either never having heard of the protocol or not having read it.

"In one of the policies it has been emphasized to us that when we have such cases [PE/E] we should attend to them promptly; we don't demand for anything first. The government really emphasizes that we have to attend to them promptly, not minding the financial aspect."

LGA Health manager, Cross River, 2018

"I don't have an idea, but I know it might exist (the policy guideline). They should disseminate the protocol now, let us see it. Maybe the physicians have seen it, but as a logistician and a pharmacist, I have not seen the protocol. I will be glad to have a copy." $\quad$ State policy-maker, Ebonyi, 2018 "I am not aware of it [the national protocol]. I'm sorry, I want to be frank."

State policy-maker, Kogi, 2018 
Increased knowledge at lower levels, at endline compared to baseline, of the national PE/E guidelines suggests that these guidelines, as important strategies for managing $\mathrm{PE} / \mathrm{E}$, are steadily reaching state and local policy-makers. While communication on the importance of strengthening PE/E management through effective policy implementation is improving, the mechanisms remain tenuous. Despite these challenges, policy-makers are dedicated to developing pragmatic solutions for maternal health challenges in their communities, including partnerships with existing community leaders and NGOs, to mitigate structural barriers such as transportation.

"It is [ANC] a problem that we are trying to correct. We discovered that fault in almost all the facilities, that first ANC is always greater than ANC 2, 3, or 4, because a woman is supposed to visit the clinic four times before she delivers. We looked at ANC generally in Cross River State, and we discussed with service delivery international non-governmental organization, after we had meetings with the chief, the youth leaders, women leaders, and other people in the ward; we have all agreed because they told us one major challenge is transportation to the clinic. So, any woman that wants to deliver anywhere-now we have provided transport."

LGA Health manager, Cross River state, 2018

Progress in strengthening $\mathrm{PHC}$ facilities and enabling their workers to detect and treat $\mathrm{PE} / \mathrm{E}$ using $\mathrm{MgSO}_{4}$ prior to referral has been made in all three states. Specific policy-maker knowledge of Nigeria's national task shifting protocol, specifically for PE/E management among lower cadres, was mixed: State policymakers knew more than LGA officials. Nearly all policy-makers support task shifting to PHC workers because they recognize the structural barriers women face for timely PE/E care at secondary or tertiary levels. According to policy-makers, a national effort has begun to re-vitalize the PHC system, by ensuring at least one PHC facility per ward is fully functional at all times, including 24 hour water supply and electricity, and sufficient personnel to meet clients' health needs.

"Task shifting is a welcome development because we only have a few nurses in the LGAs, so the task should be shifted from nurses to other health care workers so that if the nurse is not there at the community level to administer, it doesn't mean the patient should die."

Policy-maker, Cross River, 2018

While at baseline policy-makers (particularly in Ebonyi) were only moderately supportive of task shifting, citing concerns about insufficient PHC provider knowledge, training, and capacities, at endline policymakers acknowledged the successful role of this intervention's training in improving PHC providers' skills and establishing an effective treatment option for women.

"It depends on the capacity of the staff in primary care center because magnesium sulphate is not something anybody can administer...we only allow magnesium sulphate to be administered by midwives and registered nurse/midwives."

Policy-maker, Ebonyi, 2015

"At the facility level, the trainings that these health workers received have really empowered them; their capacity has been built...in 2015 many of them did not know what magnesium sulphate was but now in all the health facilities, the majority of the people trained can manage pre-eclampsia. They notice the warning signs; they give the loading dose and then refer."

State policy-maker, Ebonyi, 2018

At baseline, national $\mathrm{MgSO}_{4}$ procurement and distribution was largely unclear, with multiple, parallel state and federal procurement systems in addition to the private sector. The situation is now gradually improving. According to state policy-makers at endline, a new federal revolving fund enables secondary health facilities to purchase drugs directly from pharmacies to prevent stock outs. This revolving fund is not available to PHC facilities, which receive essential medicines and equipment, including BP machines and urine dipsticks, either directly from the government or through public-private partnership support, from NGOs or other private donors. State policy-makers report that essential medicines including $\mathrm{MgSO}_{4}$ are also available through their essential drug stores. 
"The government is providing, in conjunction with partners like Pathfinder and UNFPA-they are buying and procuring all these blood pressure apparatuses, which I know they try to provide to those facilities."

State policy-maker, Cross River, 2018

"The state has to make sure we have it in stock. I think the pharmacy department can talk more on that because $\left[\mathrm{MgSO}_{4}\right]$ is one of the essential drugs that the government is supposed to provide every quarter, using what they call DDIC that is, direct delivery inventory system, so as they're delivering, they are taking inventory of what is available so that you know when to deliver next. I don't think stockouts are still a problem for this state." State policy-maker, Ebonyi, 2018

Despite reported commodity availability and procurement options within states, local Cross River and Ebonyi policy-makers report frequent drug stock outs at tertiary and secondary facilities, citing lack of government financial support for drug purchases as the primary cause. In Kogi, strong NGO support for drug and supply procurement largely prevents stock outs, even at PHCs.

In all three states, and at all levels, policy-makers describe a variety of procurement mechanisms, from health facility purchases from community pharmacies, to individual patient purchases, to supplies from NGOs, with little evidence of coordinated efforts to ensure consistent supply. Additional progress is needed to synchronize national and state procurement processes, with coordination between the public and private sectors, to capitalize on the growing political interest throughout Nigeria for improved PE/E management.

\section{Health System}

\section{Provider knowledge of PE/E prevention}

Health care providers were asked about their knowledge of pre-eclampsia risk factors including chronic hypertension, obesity, pre-existing diabetes or diabetes in pregnancy, maternal age ( $\geq 35$ years or $<20$ years), sickle cell disease, PE/E history, kidney disease, and connective tissue diseases (Table 4). CHEWs' abilities to diagnose eclampsia improved at endline $(p=0.001)$, but there was no significant improvement in their ability to diagnose chronic hypertension and severe pre-eclampsia.

PHC providers in all three states improved their abilities to diagnose eclampsia $(p<0.001)$. Providers who reported training on maternal or child health or family planning (FP) also showed significant improvements in their ability to diagnose HDPs, from baseline to endline $(p<0.001)$.

No statistically significant differences were found among providers based upon their length of service in their respective health care units. 
TABLE 4 Provider abilities to diagnose chronic hypertension, severe pre-eclampsia, and eclampsia

Case Studies - Diagnosis pf chronic hypertension, severe preeclampsia and eclampsia in all three states

\begin{tabular}{|c|c|c|c|c|c|c|c|c|c|}
\hline & \multicolumn{3}{|c|}{$\begin{array}{l}\text { Chronic hypertension in pregnancy }{ }^{1} \\
\text { (Baseline, Total } n=149 ; \\
\text { Endline, Total } n=236 \text { ) }\end{array}$} & \multicolumn{3}{|c|}{$\begin{array}{l}\text { Severe Pre-Eclampsia }^{2} \\
\text { (Baseline, Total } n=149 ; \\
\text { Endline, Total } n=236 \text { ) }\end{array}$} & \multicolumn{3}{|c|}{$\begin{array}{c}\text { Eclampsia }^{3} \\
\text { (Baseline, Total } n=149 ; \\
\text { Endline, Total } n=236 \text { ) }\end{array}$} \\
\hline & \multicolumn{3}{|c|}{ Correct diagnosis $(n=169)$} & \multicolumn{3}{|c|}{ Correct diagnosis } & \multicolumn{3}{|c|}{ Correct diagnosis } \\
\hline & $\begin{array}{c}\text { Baseline } \\
(n=73)\end{array}$ & $\begin{array}{l}\text { Endline } \\
(\mathrm{n}=96)\end{array}$ & p-value & $\begin{array}{l}\text { Baseline } \\
(n=123)\end{array}$ & $\begin{array}{l}\text { Endline } \\
(n=217)\end{array}$ & p-value & $\begin{array}{l}\text { Baseline } \\
(n=122)\end{array}$ & $\begin{array}{l}\text { Endline } \\
(n=220)\end{array}$ & p-value \\
\hline \multicolumn{10}{|l|}{ Type of Provider, $n$ (\%)* } \\
\hline Doctors $(\mathrm{BL}=21 ; \mathrm{EL}=7)$ & $18(85.7)$ & $4(57.1)$ & $0.1^{\dagger}$ & $19(90.5)$ & $7(100.0)$ & $0.9^{\dagger}$ & $20(95.2)$ & $7(100.0)$ & $0.9^{\dagger}$ \\
\hline $\begin{array}{l}\text { Nurse/Midwife } \\
(\mathrm{BL}=71 ; \mathrm{EL}=78)\end{array}$ & $36(55.4)$ & $34(43.6)$ & 0.2 & $60(87.0)$ & $77(99.0)$ & $0.006^{\dagger}$ & $62(88.6)$ & $77(98.7)$ & $0.01^{\dagger}$ \\
\hline CHEW, CHO, Others $(\mathrm{BL}=57, \mathrm{EL}=149)$ & $19(35.9)$ & $58(38.9)$ & 0.7 & $44(80.0)$ & $133(88.1)$ & 0.1 & $40(71.4)$ & $136(90.1)$ & 0.001 \\
\hline Missing/No response & 10 & 2 & & 4 & 0 & & 2 & 0 & \\
\hline \multicolumn{10}{|l|}{ Facility Type, $n(\%) *$} \\
\hline Tertiary $(\mathrm{BL}=4 ; \mathrm{EL}=0)$ & $2(50.0)$ & $0(0.0)$ & - & $3(75.0)$ & $0(0.0)$ & - & $3(2.0)$ & $0(0.0)$ & - \\
\hline Secondary $(\mathrm{BL}=82 ; \mathrm{EL}=62)$ & $48(62.3)$ & $28(45.9)$ & 0.05 & $70(87.5)$ & $60(96.8)$ & $0.07^{\dagger}$ & $75(93.8)$ & $62(100.0)$ & $0.07^{\dagger}$ \\
\hline Primary $(\mathrm{BL}=63 ; \mathrm{EL}=174)$ & $23(39.7)$ & $68(39.3)$ & 0.9 & $50(82.0)$ & $157(90.2)$ & 0.09 & $44(69.8)$ & $158(90.8)$ & $<0.001$ \\
\hline Missing/No response & 10 & 2 & & & & & & & \\
\hline \multicolumn{10}{|l|}{ Years working in present unit/ward, $n$ (\%)* } \\
\hline$<1 y r$ & $22(33.3)$ & $19(20.4)$ & \multirow[t]{4}{*}{0.16} & $26(23.6)$ & $48(22.4)$ & \multirow[t]{4}{*}{0.2} & $29(26.6)$ & $48(22.1)$ & \multirow[t]{4}{*}{0.41} \\
\hline 1-5yrs & $26(39.4)$ & $40(43.0)$ & & $52(47.3)$ & $83(38.8)$ & & $46(42.2)$ & $86(39.6)$ & \\
\hline$>5 y r s$ & $18(27.3)$ & $34(36.6)$ & & $32(29.1)$ & $83(38.8)$ & & $34(31.2)$ & $83(38.3)$ & \\
\hline Missing/No response & 7 & 3 & & 13 & 3 & & 13 & 3 & \\
\hline \multicolumn{10}{|c|}{ Any training on maternal health, FP or child healthcare, $n(\%)^{*}$} \\
\hline Yes & $37(50.7)$ & $93(97.9)$ & \multirow[t]{2}{*}{$<0.001^{\dagger}$} & $59(48.0)$ & $206(96.3)$ & \multirow[t]{3}{*}{$<0.001$} & $56(45.9)$ & 208 (95.9) & \multirow[t]{3}{*}{$<0.001$} \\
\hline No & $36(49.3)$ & $2(2.1)$ & & $64(52.0)$ & $8(3.7)$ & & $66(54.1)$ & $9(4.1)$ & \\
\hline Missing/ No response & & 1 & & & 3 & & & 3 & \\
\hline
\end{tabular}

† Fisher's Exact; *column percentages n/N *100; ₹Nurses, Midwives, General Practitioners. BL - baseline EL-Endline

\footnotetext{
1 A pregnant woman presents at 12 weeks with BP 160/100 mmHg with no proteinuria

2 A pregnant woman presents at ANC at 30 weeks with BP $180 / 115 \mathrm{mmHg}$ and proteinuria of 2++

3 A pregnant woman developed Hypertension and significant proteins at 30 weeks. Brought back a week later with convulsion
} 
The Pritchard regimen for $\mathrm{MgSO}_{4}$ administration to prevent and treat convulsions for severe $\mathrm{PE} / \mathrm{E}$ is generally preferred and recommended in low resource settings, including Nigeria, for its ease of use. The Pritchard regimen employs both an intravenous (IV) loading dose and intramuscular (IM) maintenance doses. To successfully shift $\mathrm{MgSO}_{4}$ administration for $\mathrm{PE} / \mathrm{E}$ treatment to $\mathrm{PHC}$ workers, this intervention

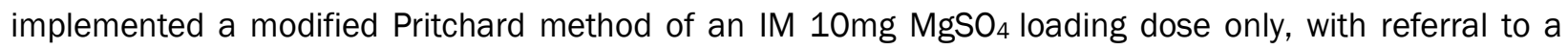
secondary facility for maintenance doses. Only 12 percent of providers knew the correct loading dose of $\mathrm{MgSO}_{4}$ at baseline, but 78 percent knew the correct loading dose at endline, a more than six-fold increase $(p<0.001)$.

TABLE 5 Correct knowledge of $\mathrm{MgSO}_{4}$ loading dose for PE/E (modified Pritchard Regime 10mg IM)

\begin{tabular}{|c|c|c|c|c|c|c|c|c|c|c|c|c|c|c|c|c|c|}
\hline & \multicolumn{4}{|c|}{ Ebonyi } & \multicolumn{4}{|c|}{ Cross River } & \multicolumn{4}{|c|}{ Kogi } & \multicolumn{3}{|c|}{ All } & & \\
\hline & \multicolumn{2}{|c|}{ Baseline } & \multicolumn{2}{|c|}{ Endline } & \multicolumn{2}{|c|}{ Baseline } & \multicolumn{2}{|c|}{ Endline } & \multicolumn{2}{|c|}{ Baseline } & \multicolumn{2}{|c|}{ Endline } & \multicolumn{2}{|c|}{$\begin{array}{l}\text { Baseline } \\
(n=149)\end{array}$} & \multirow{2}{*}{\begin{tabular}{|c|}
$\begin{array}{c}\text { Endline } \\
(n=236)\end{array}$ \\
$n$ \\
\end{tabular}} & \multicolumn{2}{|c|}{$p$-value } \\
\hline & $\mathrm{n}$ & $\%$ & $\mathrm{n}$ & $\%$ & $\mathrm{n}$ & $\%$ & $n$ & $\%$ & $\mathrm{n}$ & $\%$ & $\mathrm{n}$ & $\%$ & $n$ & $\%$ & & $\%$ & \\
\hline $\begin{array}{l}\text { Correct } \\
-10 g \\
\mathrm{MgSO}_{4}\end{array}$ & 5 & 10.9 & 71 & 79.8 & 6 & 10.2 & 56 & 75.7 & 7 & 15.9 & 58 & 79.5 & 18 & 12 & 185 & 78 & $<0.001$ \\
\hline Total & 46 & 100 & 89 & 100 & 59 & 100 & 74 & 100 & 44 & 100 & 73 & 100 & 149 & 100 & 236 & 100 & \\
\hline
\end{tabular}

\section{Provider practices for preventing PE/E}

Observations of ANC consultations assessed provider practices (see box below) for PE/E prevention, detection, and complication avoidance. Findings from observation data (Table 6) show that providers frequently measured patients' blood pressure (BP) and proteinuria, but less often assessed or communicated patients' risk for pre-eclampsia. At endline, less than one third (29\%) of all providers offered information when recognizing signs of impending eclampsia (severe pre-eclampsia) with women, although nearly half $(45 \%)$ of providers in Kogi did. At baseline, however, no providers provided patients any information about symptoms of impending eclampsia-making the endline results cited evidence of marked improvement at endline, in all three states. At both baseline and endline, in all three states, more pregnant women had physical examinations for pre-eclampsia instead of providers assessing pre-eclampsia risk and advising on symptoms of impending eclampsia.

\section{Definitions Used for ANC Consultation Observations}

Assessing risk of pre-eclampsia: History of hypertension/high BP, history of diabetes, asked about date of last delivery, client weight, pregnancy order, and client age

Detecting pre-eclampsia: Client's BP and urinalysis (protein/albumin)

Advising on symptoms of impending eclampsia: Severe headache, blurred vision, high BP, and generalized body swelling.

TABLE 6 Observations of client and provider interactions

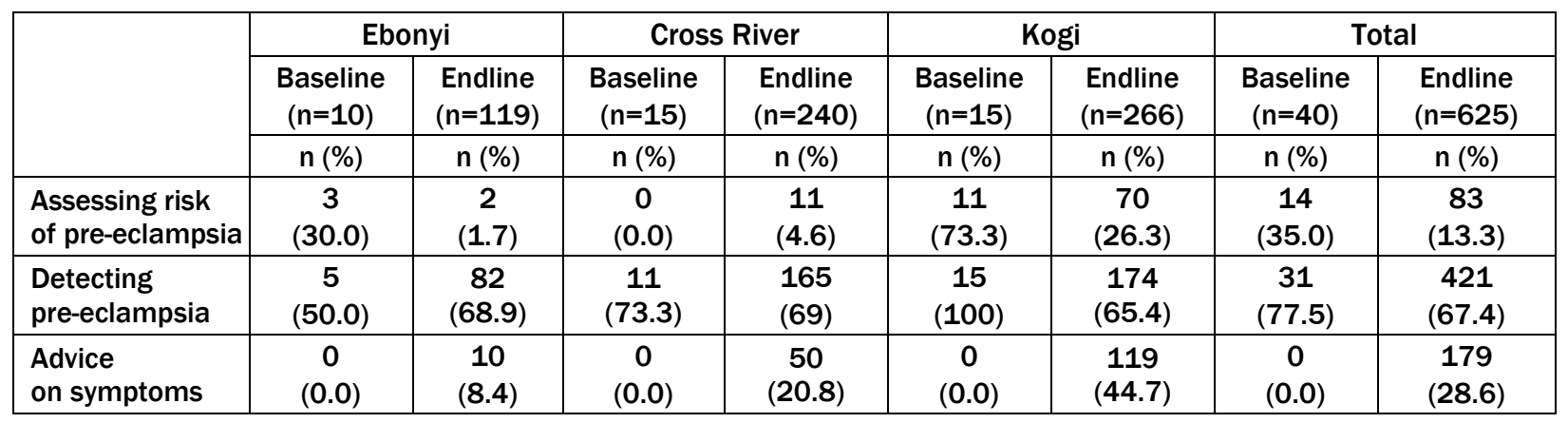


For the seven total variables that measured provider practices for assessing pre-eclampsia risk, summary scores for each observation show the number of variables actually exhibited ( 0 representing no risk assessment observed, up to 6 representing all six variables assessed). While there were overall improvements in provider assessments of two to three risk factors at endline, there appears to be lesser improvements for provider assessments of all six risk factors. The two most frequently assessed factors at endline were client weight (94.4\%), and age (53.3\%); questions around hypertension, diabetes, and last delivery were less frequently asked (23\% to $30 \%)$.

Figure 3 Pre-eclampsia risk assessment scores observed during ANC client-provider interactions

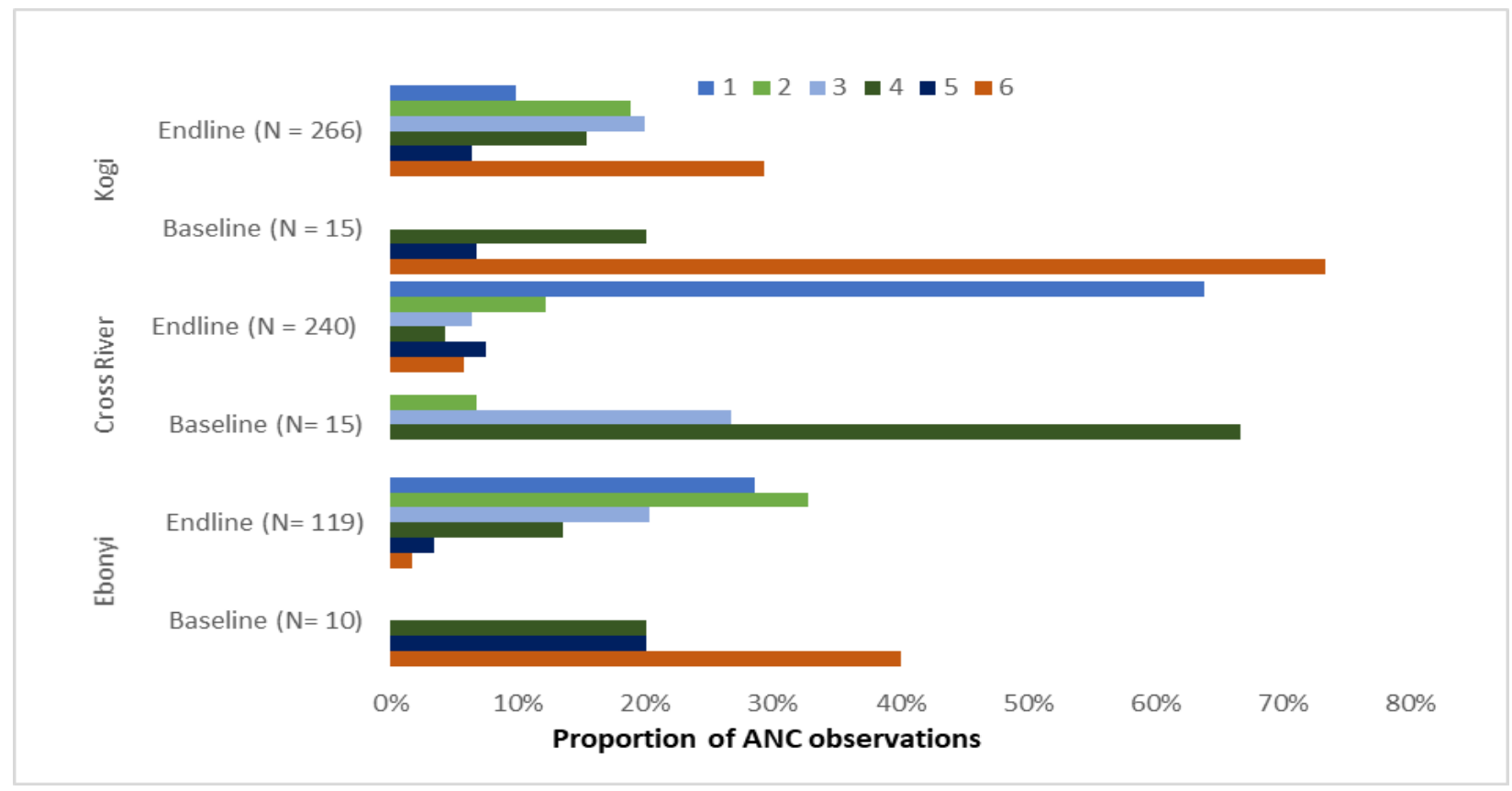

Summary scores for each observation show whether or not a provider correctly checked for pre-eclampsia (up to 2 indicators), including BP and proteinuria testing, at baseline and endline (dis-aggregated by state). A clear and significant improvement in measuring at least one, as well as both, was observed overall, in each state, suggesting that the primary intervention's emphasis on early detection and management was successful, although more so with BP checks (97.1\%) than proteinuria testing (69.3\%) (data not shown).

Figure 4 ANC observation summaries of pre-eclampsia detection scores

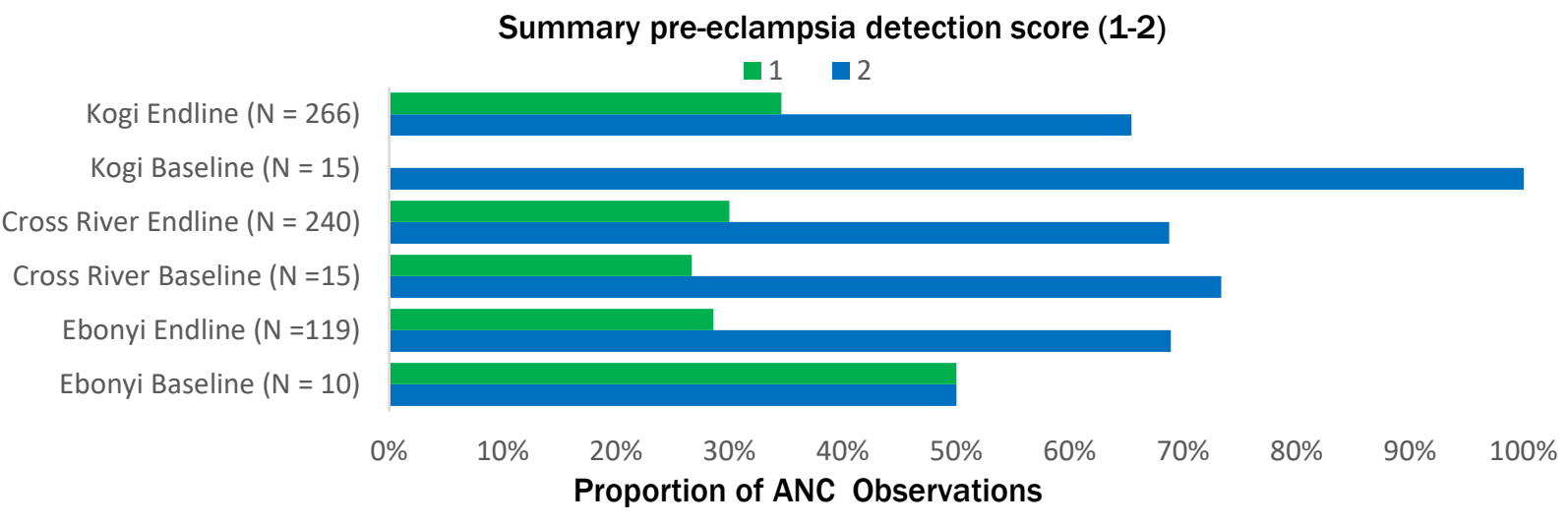


Four variables measured provider practice on advising women with severe pre-eclampsia symptoms to prevent eclampsia and other complications. Summary scores generated for each observation show the aggregate number of symptoms on which advice was provided ( 0 representing none, up to 4 representing advice for all 4 symptoms).

Results are mixed on provider advice on different pre-eclampsia symptoms; while some providers at endline still did not advise on any symptoms, quite a few provided advice on all four symptoms. The relative consistency of this pattern in all three states likely reflects the challenges in PHC provider attrition or transfers, which may have limited the reach of training and mentoring within the primary intervention. At endline, improvements for all symptoms were seen: Severe headache was the symptom most frequently advised (58.2\%), followed by high BP (49.4\%), then generalized body swelling (45.4\%), and blurred vision (41.7\%). In Kogi state no provider at baseline advised on any sign or symptom of severe pre-eclampsia.

Figure 5 ANC observation summaries of symptom advice scores

Summary Symptom Advice Score (0-4)

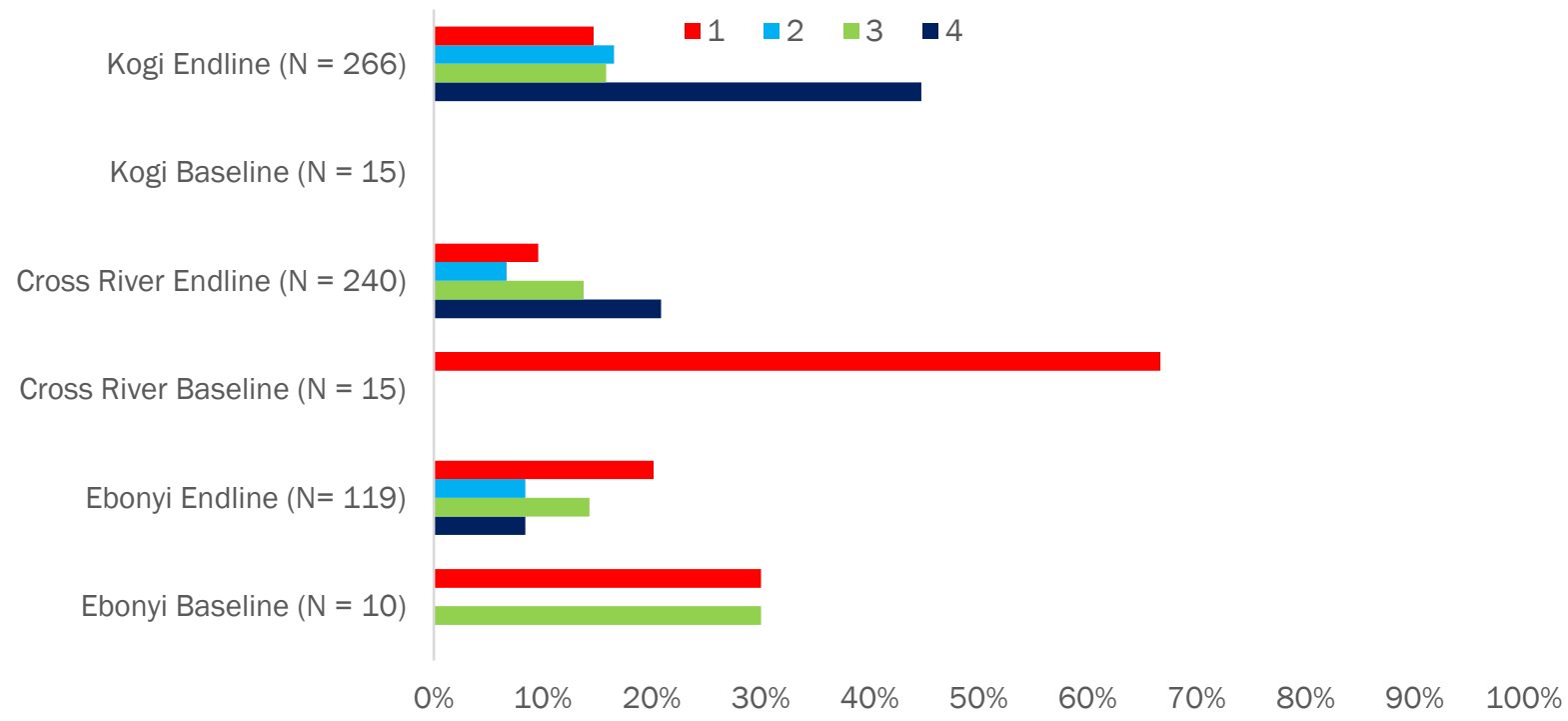

Proportion of ANC Observations

\section{Detection and management for pre-eclampsia: monitoring data}

In the primary Ending Eclampsia intervention, PHC providers were trained and mentored to pro-actively document their process of pre-eclampsia detection for timely management, including delivery and referral if appropriate. This documentation allowed the project to monitor how women were diagnosed and managed.

High risk pregnancies related to age, defined as pregnant women ages 15 to 19 and over 35 years, were relatively common (5.7\% and $21.6 \%$, respectively). Among women whose BP was recorded at registration (153 women), nearly one half were already hypertensive. The medical histories of this cohort reveal low proportions of risk factors associated with pre-eclampsia, such as history of hypertension, diabetes, or previous pre-eclampsia. Late ANC registration was common: Only about 7.3 percent of women registered for ANC in their first trimester. 
TABLE 7 Characteristics of Pregnant Women Enrolled with PE/E-All States

\begin{tabular}{|c|c|c|c|c|}
\hline \multirow[t]{2}{*}{ Characteristics } & $\begin{array}{c}\text { Cross River } \\
(n=81)\end{array}$ & $\begin{array}{l}\text { Ebonyi } \\
(n=55)\end{array}$ & $\begin{array}{c}\text { Kogi } \\
(n=40)\end{array}$ & $\begin{array}{c}\text { Total } \\
(n=176)\end{array}$ \\
\hline & n (\%) & n (\%) & n (\%) & n (\%) \\
\hline $\begin{array}{r}15-25 \\
>25-35 \\
>35-45 \\
\quad \text { Missing }\end{array}$ & $\begin{array}{c}25(32.1) \\
39(50.0) \\
14(17.9) \\
3\end{array}$ & $\begin{array}{c}22(46.8) \\
17(36.2) \\
8(17.0) \\
8\end{array}$ & $\begin{array}{c}11(29.0) \\
22(57.9) \\
5(13.1) \\
2\end{array}$ & $\begin{array}{l}58(35.5) \\
78(47.9) \\
27(16.6) \\
13\end{array}$ \\
\hline $\begin{array}{l}\text { Married } \\
\text { Single } \\
\text { Missing }\end{array}$ & $\begin{array}{c}62(76.5) \\
19(23.5 \\
0 \\
\end{array}$ & $\begin{array}{c}48(88.9) \\
6(11.1) \\
1 \\
\end{array}$ & $\begin{array}{c}36(92.3) \\
3(7.7) \\
1\end{array}$ & $\begin{array}{c}146(83.9) \\
28(16.1) \\
2\end{array}$ \\
\hline $\begin{array}{r}0^{\wedge} \\
1 \\
2 \\
3 \\
>3 \\
\text { Missing } \\
\end{array}$ & $\begin{array}{c}20(25.3) \\
28(35.4) \\
9(11.4) \\
7(8.9) \\
15(19.0) \\
2 \\
\end{array}$ & $\begin{array}{c}8(15.1) \\
24(45.2) \\
7(13.2) \\
4(97.6) \\
10(18.9) \\
2 \\
\end{array}$ & $\begin{array}{c}6(16.2) \\
10(27.1) \\
8(21.6) \\
8(21.6) \\
5(13.5) \\
3 \\
\end{array}$ & $\begin{array}{c}34(20.1) \\
62(36.7) \\
24(14.2) \\
19(11.2) \\
30(17.8) \\
7 \\
\end{array}$ \\
\hline $\begin{array}{r}\text { Booking blood pressure } \\
\qquad \begin{array}{r}<140 / 90 \mathrm{mmhg} \\
\geq 140 / 90 \mathrm{mmhg} \\
\text { Missing }\end{array}\end{array}$ & $\begin{array}{c}47(67.1) \\
23(32.9) \\
11\end{array}$ & $\begin{array}{c}20(43.5) \\
26(56.5) \\
9\end{array}$ & $\begin{array}{c}18(48.6) \\
19(51.4) \\
3\end{array}$ & $\begin{array}{c}85(55.6) \\
68(44.4) \\
23\end{array}$ \\
\hline $\begin{array}{l}\text { Proteinuria on booking } \\
0 \text { (not-detectable) } \\
+1 \\
+2 \\
+3 \\
+4 \\
\text { Missing }\end{array}$ & $\begin{array}{l}49(74.3) \\
7(10.6) \\
7(10.6) \\
3(4.5) \\
0(0.0) \\
15\end{array}$ & $\begin{array}{c}18(40.9) \\
8(18.2) \\
10(22.7) \\
7(15.9) \\
1(2.3) \\
11\end{array}$ & $\begin{array}{l}20(57.1) \\
5(14.3) \\
7(20.0) \\
3(8.6) \\
0(0.0) \\
5\end{array}$ & $\begin{array}{c}87(60.0) \\
20(13.8) \\
24(16.6) \\
13(9.0) \\
1(0.6) \\
31\end{array}$ \\
\hline  & $\begin{array}{c}0(0.0) \\
3(4.5) \\
1(1.5) \\
4(6.1) \\
1(1.5) \\
45(68.2) \\
12(18.2) \\
15\end{array}$ & $\begin{array}{c}1(1.9) \\
0(0.0) \\
0(0.0) \\
0(0.0) \\
0(0.0) \\
41(78.9) \\
10(19.2) \\
3\end{array}$ & $\begin{array}{c}1(2.8) \\
4(11.1) \\
0(0.0) \\
1(2.8) \\
0(0.0) \\
28(77.8) \\
2(5.6) \\
4\end{array}$ & $\begin{array}{c}2(1.3) \\
7(4.6) \\
1(0.6) \\
5(3.2) \\
1(0.6) \\
114(74.1) \\
24(15.6) \\
22 \\
\end{array}$ \\
\hline $\begin{array}{r}\text { Gestational Age at booking (weeks) } \\
0-12 \\
13-27 \\
28-42 \\
\text { Missing }\end{array}$ & $\begin{array}{c}5(7.1) \\
32(45.7) \\
33(47.2) \\
11\end{array}$ & $\begin{array}{c}3(6.7) \\
14(31.1) \\
28(62.2) \\
10 \\
\end{array}$ & $\begin{array}{c}3(8.3) \\
17(47.2) \\
16(44.5) \\
4\end{array}$ & $\begin{array}{c}11(7.3) \\
63(41.7) \\
77(51.0) \\
25 \\
\end{array}$ \\
\hline
\end{tabular}

GA, Gestational age; CS, Caesarean section, PE/E, Pre-eclampsia/Eclampsia tincludes formerly married (divorced, widowed).

At enrolment in this study, 20.5 percent of women were diagnosed with pre-eclampsia, 74.4 percent with severe pre-eclampsia, and 3.4 percent with eclampsia. Only 61.8 percent of those diagnosed with severe pre-eclampsia received $\mathrm{MgSO}_{4}$, perhaps due to health system limitations such as stock outs.

Referral trends among women diagnosed with pre-eclampsia and severe PE/E differed by state: Women in Ebonyi were more frequently referred to higher level facilities for follow up care. Of the 176 women enrolled, only 130 had their gestational age recorded at delivery, and among those women, 53.9 percent delivered pre-term (less than 38 weeks) and 46.1 percent at term ( $\geq 38$ weeks). Similarly, 154 of the 176 women with pre-eclampsia had their mode of delivery documented: 45.4 percent had a Caesarean delivery, 44.2 percent had spontaneous vaginal delivery, and 10.4 percent were induced for vaginal delivery. State differences also manifest with mode of infant delivery, with more Caesarean deliveries in Cross River (56.8\%). 
TABLE 8 Diagnosis and management on enrollment among monitored women

\begin{tabular}{|c|c|c|c|c|}
\hline & $\begin{array}{c}\text { Cross River } \\
(n=81)\end{array}$ & $\begin{array}{l}\text { Ebonyi } \\
(n=55)\end{array}$ & $\begin{array}{c}\text { Kogi } \\
(n=40)\end{array}$ & $\begin{array}{c}\text { Total } \\
(n=176)\end{array}$ \\
\hline & $\mathrm{n}(\%)$ & $\mathrm{n}(\%)$ & n (\%) & $\mathrm{n}(\%)$ \\
\hline \multirow[t]{4}{*}{ Diagnosis at enrollment/recruitmen } & $15(18.5)$ & $14(25.5)$ & $7(17.5)$ & $36(20.5)$ \\
\hline & $63(77.8)$ & $38(69.1)$ & $30(75.0)$ & $131(74.4)$ \\
\hline & $3(3.7)$ & $2(3.6)$ & $1(2.5)$ & $6(3.4)$ \\
\hline & 0 & $1(1.8)$ & $2(5.0)$ & $3(1.7)$ \\
\hline $\begin{array}{l}\text { Received } \mathrm{MgSO}_{4} \text { upon severe pre-eclampsia diagnosis } \\
\text { at enrollment* }\end{array}$ & $42\left(66.7^{*}\right)$ & $22(57.9 *)$ & $17\left(56.7^{*}\right)$ & $\begin{array}{c}81 \\
(61.8 *) \\
\end{array}$ \\
\hline Referred from PHC on enrollment & $15(18.5)$ & $24(43.6)$ & 5 (12.5) & $44(25.0)$ \\
\hline \multirow[t]{3}{*}{ Gestation at delivery } & $37(56.9)$ & $10(30.3$ & $21(71.9)$ & $70(53.9)$ \\
\hline & 28 (43.1) & $23(69.7)$ & $11(28.1)$ & 60 (46.1) \\
\hline & 16 & 22 & 8 & 46 \\
\hline \multirow[t]{4}{*}{ Mode of delivery } & $26(35.1)$ & $25(56.8)$ & $17(47.2)$ & $68(44.2)$ \\
\hline & $6(8.1)$ & $7(15.9)$ & $3(8.3)$ & $16(10.4)$ \\
\hline & $42(56.8)$ & $12(27.3)$ & $16(44.5)$ & $70(45.4)$ \\
\hline & 7 & 11 & 4 & 22 \\
\hline
\end{tabular}

Maternal outcomes (dead or alive) were recorded for 157 of the 176 women who were followed until delivery. Among those, 96.8 percent of mothers survived, with 3.2 percent recorded as maternal deaths. Available mortality information $(n=34)$ reveal stillbirths and early neonatal deaths for 50 percent of the infants. Infant death records were more consistently recorded in Ebonyi.

Table 9 Pregnancy outcomes among monitored women

\begin{tabular}{|c|c|c|c|c|}
\hline & $\begin{array}{c}\text { Cross River } \\
(\mathbf{n}=\mathbf{8 1})\end{array}$ & $\begin{array}{l}\text { Ebonyi } \\
(n=55)\end{array}$ & $\begin{array}{c}\text { Kogi } \\
(n=40)\end{array}$ & $\begin{array}{c}\text { Total } \\
(n=176)\end{array}$ \\
\hline & n (\%) & n (\%) & n (\%) & n (\%) \\
\hline $\begin{array}{r}\text { Alive } \\
\text { Dead } \\
\text { Missing }\end{array}$ & $\begin{array}{c}73(98.7) \\
1(1.3) \\
7\end{array}$ & $\begin{array}{c}44(95.7) \\
2(4.3) \\
9\end{array}$ & $\begin{array}{c}35(94.6) \\
2(5.4) \\
3\end{array}$ & $\begin{array}{c}152(96.8) \\
5(3.2) \\
19\end{array}$ \\
\hline $\begin{array}{r}\text { Alive } \\
\text { Dead } \\
\text { Missing }\end{array}$ & $\begin{array}{c}63(85.1) \\
11(14.9) \\
7\end{array}$ & $\begin{array}{c}31(62.0) \\
19(38.0) \\
5\end{array}$ & $\begin{array}{c}26(74.3) \\
9(25.7) \\
5\end{array}$ & $\begin{array}{c}120(74.5) \\
39(24.5) \\
17\end{array}$ \\
\hline Fetal death by category, $\mathrm{n}(\%)$ & $(n=11)$ & $(n=19)$ & $(n=9)$ & $(n=39)$ \\
\hline $\begin{array}{r}\text { Dead (not categorized) } \\
\text { Stillbirth } \\
\text { Early neonatal death } \\
\text { No information }\end{array}$ & $\begin{array}{c}7(77.8) \\
2(22.2) \\
0(0.0) \\
2\end{array}$ & $\begin{array}{c}7(43.7) \\
6(37.5) \\
3(18.8) \\
3\end{array}$ & $\begin{array}{l}3(33.3) \\
6(66.7) \\
0(0.0) \\
0(0.0)\end{array}$ & $\begin{array}{c}17(50.0) \\
14(41.2) \\
3(8.8) \\
5\end{array}$ \\
\hline
\end{tabular}

\section{Commodity and supply chain for emergency hypertension management}

\section{Health facility assessments}

At endline, nearly three quarters of facilities stocked anti-hypertensive drugs and $\mathrm{MgSO}_{4}$, significantly more than at baseline $(p<0.001)$. Despite it being a non-significant increase, the proportion of facilities stocking calcium gluconate to treat $\mathrm{MgSO}_{4}$ toxicity increased from 13 percent to 70 percent from baseline to endline. Patella hammers (used to test knee reflexes, a sign of toxicity) were infrequently found both at baseline (5\%) and endline (14\%). 
TABLE 10 Facilities with key drugs and equipment to manage severe $\mathrm{PE} / \mathrm{E}$ and observe for $\mathrm{MgSO}_{4}$ toxicity

\begin{tabular}{|l|c|c|c|c|c|c|c|c|}
\hline \multirow{2}{*}{$\begin{array}{l}\text { Drugs and } \\
\text { equipment }\end{array}$} & \multicolumn{2}{|c|}{ Ebonyi } & \multicolumn{2}{c|}{ Cross River } & \multicolumn{2}{c|}{ Kogi } & \multicolumn{2}{c|}{ Total } \\
\cline { 2 - 9 } & $\begin{array}{c}\text { Baseline } \\
(\mathrm{n}=20)\end{array}$ & $\begin{array}{c}\text { Endline } \\
(\mathrm{n}=57)\end{array}$ & $\begin{array}{c}\text { Baseline } \\
(\mathrm{n}=11)\end{array}$ & $\begin{array}{c}\text { Endline } \\
(\mathrm{n}=54)\end{array}$ & $\begin{array}{c}\text { Baseline } \\
(\mathrm{n}=8)\end{array}$ & $\begin{array}{c}\text { Endline } \\
(\mathrm{n}=60)\end{array}$ & $\begin{array}{c}\text { Baseline } \\
(\mathrm{n}=39)\end{array}$ & $\begin{array}{c}\text { Endline } \\
(\mathrm{n}=171)\end{array}$ \\
\cline { 2 - 9 } & $\mathrm{n}(\%)$ & $\mathrm{n}(\%)$ & $\mathrm{n}(\%)$ & $\mathrm{n}(\%)$ & $\mathrm{n}(\%)$ & $\mathrm{n}(\%)$ & $\mathrm{n}(\%)$ & $\mathrm{n}(\%)$ \\
\hline Anti-hypertensives & $1(5.0)$ & $37(64.9)$ & $0(0.0)$ & $25(46.3)$ & $3(37.5)$ & $49(81.7)$ & $4(10.3)$ & $111(65.0)$ \\
\hline MgSO & $5(25.0)$ & $47(82.4)$ & $5(45.5)$ & $28(52.0)$ & $2(25.0)$ & $47(78.3)$ & $12(30.8)$ & $122(71.3)$ \\
\hline $\begin{array}{l}\text { Calcium } \\
\text { Gluconate }\end{array}$ & $2(10.0)$ & $44(77.2)$ & $2(18.2)$ & $34(63.0)$ & $1(12.5)$ & $41(68.3)$ & $5(12.8)$ & $119(69.6)$ \\
\hline Patella Hammer & $1(5.0)$ & $5(8.8)$ & $0(0.0)$ & $14(25.9)$ & $1(12.5)$ & $5(8.3)$ & $2(5.1)$ & $24(14.0)$ \\
\hline Urine Catheter & $9(45.0)$ & $23(40.3)$ & $5(45.5)$ & $32(59.3)$ & $5(62.5)$ & $40(66.7)$ & $19(48.7)$ & $95(55.6)$ \\
\hline Urine Bag & $3(15.0)$ & $15(26.3)$ & $4(36.4)$ & $16(29.6)$ & $4(50.0)$ & $24(40.0)$ & $11(28.2)$ & $55(32.2)$ \\
\hline
\end{tabular}

Facility capacities for EmONC signal functions, and records of them, in the previous three months (dependent on stock and need) remained fairly constant-and mixed-between baseline and endline (Table 11). Improved capacities were reported for stocking parenteral antibiotics, oxytocics, $\mathrm{MgSO}_{4}$, and neonatal resuscitation equipment. Facility administration of parenteral antibiotics and neonatal resuscitation, in the preceding three months, also increased at endline. Disparities between facility reports of EmONC capacity compared with actual practice, in the preceding three months-at both baseline and endline-corresponds with the primary intervention's lack of focus on comprehensive EmONC, except for $\mathrm{MgSO}_{4}$.

TABLE 11 Signal Functions for EmONC

\begin{tabular}{|l|c|c|c|c|}
\hline Signal function & $\begin{array}{c}\text { Baseline } \\
(\mathrm{n}=39)\end{array}$ & $\begin{array}{c}\text { Endline } \\
(\mathrm{n}=171)\end{array}$ & $\begin{array}{c}\text { Baseline } \\
(\mathrm{n}=39)\end{array}$ & $\begin{array}{c}\text { Endline } \\
(\mathrm{n}=171)\end{array}$ \\
\hline & $\begin{array}{c}\text { Capacity } \\
\mathrm{n}(\%)\end{array}$ & $\begin{array}{c}\text { Capacity } \\
\mathrm{n}(\%)\end{array}$ & $\begin{array}{c}\text { Within past 3 } \\
\text { months } \\
\mathrm{n}(\%)\end{array}$ & $\begin{array}{c}\text { Within past 3 } \\
\text { months } \\
\mathrm{n}(\%)\end{array}$ \\
\hline Parenteral antibiotics & $30(77.0)$ & $146(85.3)$ & $25(64.1)$ & $120(70.2)$ \\
\hline Parenteral oxytocics & $32(82.1)$ & $151(88.3)$ & $31(79.5)$ & $134(78.4)$ \\
\hline Parenteral anticonvulsants $\left(\mathrm{MgSO}_{4}\right)$ & $18(46.2)$ & $115(67.3)$ & $13(33.3)$ & $48(28.1)$ \\
\hline Manual placenta removal & $32(82.1)$ & $135(79.0)$ & $20(51.3)$ & $80(46.7)$ \\
\hline Retained products removal & $27(69.2)$ & $115(67.3)$ & $23(59.0)$ & $63(36.8)$ \\
\hline Assisted vaginal delivery & $27(69.2)$ & $88(51.5)$ & $21(53.8)$ & $72(42.1)$ \\
\hline Blood transfusion & $18(46.2)$ & $56(32.7)$ & $15(38.5)$ & $35(20.5)$ \\
\hline Caesarean section & $12(30.7)$ & $30(17.5)$ & $11(28.2)$ & $21(12.3)$ \\
\hline Neonatal resuscitation & $25(64.1)$ & $138(80.7)$ & $18(46.2)$ & $98(57.3)$ \\
\hline
\end{tabular}

\section{Drug store manager survey findings}

Although the project did not interview drug store managers at baseline, it became evident during implementation that essential commodities and medicines to manage PE/E were not being procured by secondary facilities. Following discussions with state MoHs, a one day workshop for drug stores and pharmacy workers was presented on specific maternal health commodities. As a result, 35 drug stores managers at secondary health facilities (11 from Ebonyi, 11 from Cross River, 13 from Kogi) were interviewed only at endline to understand supply and commodity availability and logistics management practices for pre-eclampsia treatment (data not shown). Most drug stores managers were between 40 and 49 years of age, 60 percent were male, and most were pharmacist technicians (54.3\%), and then pharmacists $(42.9 \%)$ or pharmacy technologists (2.9\%). Just under two thirds (62.9\%) of drug stores managers had over five years' experience in their current positions, and at their facilities in general. 
Although the project provided supply chain logistics support training, some drug stores managers (28.6\%) reported lack of training in medicine management within the last 12 months. Moreover, only 40 percent said they had received any training on EmOC.

A majority of the trained drug store managers (88.6\%) said they did not have sufficient opportunities to practice what they had learned, and think more practical sessions are required to build their confidence. All drug stores managers were familiar with medicines for preventing and treating eclampsia convulsion and are aware that they are on the essential drug list. Most (82.9\%) drug stores managers could recall storage guidelines for $\mathrm{MgSO}_{4}$ and calcium gluconate, while around two thirds (65.7\%) said they personally manage stocks of uterotonic and pre-eclampsia medicines.

\section{Community Perceptions and Understanding of PE/E}

Understanding of the causes of PE/E within communities largely improved since baseline. At baseline, PE/E symptoms and causes of HDP were attributed to spiritual attacks, evil spirits, and witchcraft, and those associations were less prevalent at endline, particularly in Cross River and Ebonyi. In Kogi, community members emphasized religious leaders' influences in reinforcing the belief that HDP and other PE/E symptoms are caused by spiritual attack. Despite these misperceptions, community members in all three states knew that ANC registration is integral to a healthy pregnancy as well as PE/E prevention and management. Although the men interviewed did accompany their wives to ANC visits, they reported encouraging ANC registration. Women in FGDs reported, however, that their husbands are most likely to take their wives to hospitals, instead of traditional birth attendants (TBAs), in cases of pregnancy complications.

Health system trust among community members improved significantly in all the three states, with community members (including husbands and mothers-in-law) emphasizing the importance of facilitybased care and ANC registration to address pregnancy complications.

"They normally go to see doctors or nearest health facility to seek care. This is because they have learnt that it is proper and important to see a doctor to check them and their unborn baby."

Female FGD participant, Ebonyi, 2018

Traditional health care elements still exist in all three states, but community members described these as complementary to the formal health system, rather than functioning in opposition to it. In Ebonyi religious leaders and TBAs are not directly involved in the formal health system, and at endline FGD participants less frequently mentioned TBAs as a woman's primary delivery preference, which suggests that these traditional health-seeking practices are becoming less common as women and communities begin to trust and engage more frequently with the formal health system.

In Kogi and Cross River, community members described some women as seeking facility-based care, while others continue to prefer traditional healers. Community members in these states report that religious leaders' primary influences upon women's health-seeking behaviors are through prayer and the delineation of the distinct roles of traditional caregivers and the formal health system as complementary in women's health and pregnancy care.

"The religious leaders concern themselves only to praying for women with health problems, but the restriction is that they cannot transfuse blood into a woman who needs blood, which is done only at the hospital. If the religious leader does their part, the hospital likewise has its own part."

Female FGD participant, Cross River, 2018

"They [church leaders] also help in other means like if there is any program being proposed by the health workers, they will announce it in the church."

Male FGD participant, Ebonyi, 2018 
Overall, community members support pregnant women's health care-seeking and offer emotional and material support whenever possible. Although men are concerned with the costs of their wives' ANC and hospital care, they stressed the importance of being a supportive husband and ensuring their wives receive adequate care during pregnancy. Many mothers-in-law equally encourage their daughters-in-law to seek facility-based care, although some Kogi community members report dismissive attitudes of some mothersin-law, who describe their daughters-in-law as simply 'lazy' or 'pretending' to have hypertensive symptoms.

"Some mother in-laws [sic] would be happy; they would even pamper the daughter in-law. On the other hand, there are mother in-laws that would feel that the daughter in-law is too lazy. If you suggest going to the hospital, some mothers could say the pregnant daughter in-law just want to waste their sons' money. At that point they'd start suggesting home remedies."

Female FGD participant, Kogi, 2018

"Our mother in-laws [sic], since many...don't live with us in the house, they know these problems through us. When my wife is pregnant, even though I am going far, I make sure when I am back I stay around her, and discuss with her closely how she is feeling, and if I observe anything I try to inform my mother in-law because she is a mother, so that she can advise on the next line of action."

Male FGD participant, Cross River, 2018

"We need to tell women the importance of prenatal care and give them financial support. But the main thing is to tell them the importance of it." Male FGD participant, Ebonyi, 2018

Inability to attend ANC or seek facility-based care are attributed to financial barriers, specifically hospital bills and treatment costs, rather than transportation costs, ignorance of the importance of ANC, or continuing preference for traditional birth practices. At baseline, community stakeholders blamed lack of transportation support and ignorance more than at endline. In at least one community in Cross River, the distance to health facilities and access disparities among women living closer to the main road and those farther affected women's care-seeking behaviors.

"Well if my wife complains problem and I take her to the hospital, you know those pharmacy Doctors complain too much about money, if am a man and am working, there is no complaint she will give that will not be able to solve because she is my wife and I love her."

Male FGD participant, Cross River, 2018

"My view as the man of the house is that the government loves us so much by sending you as a facilitator over this program, the government should not only send you to come and gather ideas from us, the government should also see what we are discussing and make these things available to our women."

Male FGD participant, Cross River, 2018

Persistent community perceptions of insupportable personal expenditures as barriers to care are of deep concern, considering policy-makers' earlier descriptions of pregnancy complication care as low cost or free.

\section{PE/E Survivor Experiences}

At baseline, over half of PE/E survivors said they first registered for ANC only when they began experiencing complications or adverse symptoms during pregnancy. At endline, not only did all survivors interviewed register for ANC prior to complications, more than 83 percent reported registering because they knew that contact with a formal ANC clinic is important for healthy pregnancy. Many women reported at least four ANC contacts (range 1 to 10+), although survivors continue to report delayed registration, nearly always after the first trimester. One survivor registered at two months' gestation and attended eight ANC sessions; a second survivor reported visiting a hospital at two months' gestation to confirm her pregnancy but chose not to formally register for ANC until her fourth month of pregnancy, citing her desire to maintain the pregnancy a secret until she had reached at least three months' gestation. 
“O.K., it was, it was fine, it was great because I never wanted people, I went there when it was two months and I never let people know, the workers there...they talk a lot, they might say 'Oh! This person has registered with us, she is pregnant.' So, I didn't, I told doctor that they should just run a test, but he should have his record, when I come, when I am three or four months then I can now come and register with them. So that was what they did."

PE/E Survivor, Cross River, 2018

"I knew I was supposed to register even without any problems, I know it so that was why I went there to register." PE/E Survivor, Cross River, 2018

"I can't really recall but I have been going there monthly, I registered at four months, then have been going there monthly then by eight months, eight months getting to nine months was now weekly."

PE/E Survivor, Cross River, 2018

As at baseline, urine and BP are routinely checked during ANC visits, and women's reports corroborate observational findings that multiple key components of ANC are now routine, including abdomen checks and fetal heartbeat monitoring. Women in all three states at endline consistently received both urine and BP checks and test results-an improvement from baseline-and women are knowledgeable about what constitutes dangerous BP and proteinuria levels.

"The blood pressure started from 165 when they noticed [pre-eclampsia]. That day I just went for ANC and after checking the blood pressure [it was high] it started from 165 and before delivery it ran to 195 over 140."

PE/E Survivor, Ebonyi, 2018

While women and providers increasingly dialogue about women's test results as PE/E symptoms occur, in all three states few women reported thorough explanations about the implications of their results, despite asking for more information. One survivor described better quality information in her first pregnancy than during her second when she attended ANC at a different hospital, suggesting that provider-patient discussions, beyond strictly clinical test results, vary by location.

Women in all three states are more aware than ever of the importance of ANC for healthy pregnancies, and many women are interested in learning more during their ANC visits, evidenced in part by the 50 percent of women who actively asked questions during their observed ANC appointments.

"You know that they do not tell us all these things in all the hospitals. I know what you are talking about. During my first pregnancy, I went for antenatal in Uburu; those people will teach you all these things and make you to understand them all."

PE/E Survivor, Ebonyi, 2018

"He did not tell me what they saw in my urine. I asked so that they will explain to me, but they did not. I think they told my husband, I will ask him later. I was not told [the implications], but I was told to avoid anything that will make me sad or angry."

PE/E Survivor, Ebonyi, 2018 


\section{Discussion}

This report describes results of a pre-post intervention to build the capacities of PHC providers for managing $\mathrm{PE} / \mathrm{E}$ at lower levels of Nigeria's health system. An important approach for preventing deaths and severe morbidities from pre-eclampsia is PHC providers' abilities to detect pre-eclampsia early and take appropriate action, including infant delivery or prompt referrals when indicated.

For this PHC model to work effectively, health care facilities must be supported by regular essential commodity $\left(\mathrm{MgSO}_{4}\right.$, anti-hypertensive drugs, urine dipsticks, calcium gluconate) and equipment (BP measuring machines and patella hammers) supplies. Women should also be given opportunities to ask questions about their and their infants' health during ANC and PNC consultations. Active community engagement with women, through various social platforms, should motivate women to take charge of their health and seek relevant care from facilities in a timely manner. This project's interventions addressed these aspects together, under the PE/E PHC model of care that was tested.

Provider abilities for routine assessment of pre-eclampsia improved, along with its management according to current WHO recommendations for PE/E prevention and treatment (WHO 2015). At baseline, no provider proactively checked for pre-eclampsia. Although progress was marginal, given HDP prevalence in Nigeria the impacts of this study's progress, if scaled nationally, would be large, as PHC providers trained now have the capacity to detect and manage pre-eclampsia and administer loading doses of $\mathrm{MgSO}_{4}$ in appropriate cases (Danmusa, Coeytaux, Potts, Wells 2016, Khandekar, Patil, Pawar, Rajgure, Suryavanshi 2011, Oguntunde et al. 2015).

This project engendered new energy and commitment, with consistent and strong support from policymakers to extend task shifting to $\mathrm{PHC}$ providers for $\mathrm{MgSO}_{4}$ loading doses and referrals. The immediate benefit of this policy shift, and the supportive environment, was demonstrated through PHC providers' proven capacities to detect, treat, and manage HDP and PE/E by administering $\mathrm{MgSO}_{4}$ loading doses using a modified Pritchard regimen of $10 \mathrm{mg} \mathrm{MgSO}_{4}$ (in conjunction with other treatment and timely delivery) and referrals. The original Pritchard regimen is based on a loading of $14 \mathrm{~g}$, divided into $4 \mathrm{~g}$ IV and $10 \mathrm{~g} \mathrm{IM} \mathrm{(5g} \mathrm{in}$ each buttock), and this modification eliminates the initial $4 \mathrm{~g}$ IV dose and only provides the $5 \mathrm{~g} I \mathrm{M}$ doses, making it simpler and more convenient to administer in a PHC setting, where providers have less experience in IV medicines. Other studies and countries use this modified dose (Bangladesh, CLIP Trials). WHO is leading work on understanding the actual sufficient minimum $\mathrm{MgSO}_{4}$ loading and maintenance doses (Okusanya et al. 2016).

Building the capacity of PHC providers to better diagnose HDP and provide prompt care based on its type and severity is a major advance for how HDP is managed in Nigeria and a contributor to overall improvement in HDP care in Nigeria. Before now, the local task shifting policy only referenced provision of $\mathrm{MgSO}_{4}$ loading dose at a PHC facility, while remaining silent on HDP management. Other studies have reported the success of this approach (FMoH 2014, Singh, Ahmed, Egondu, Ikechukwu 2014, Townsend, Brien, Khalil 2016).

While communication of the importance of strengthening PE/E management through effective policy implementation has improved, the mechanisms remain somewhat tenuous. Despite challenges, policymakers are dedicated to developing pragmatic solutions to maternal challenges in their communities, including partnerships with both the private and non-profit sectors. Progress has been made in all three states for strengthening PHC systems and enabling their workers to manage and treat PE/E using $\mathrm{MgSO}_{4}$. Specific knowledge of Nigeria's national task shifting protocol for PE/E management to lower health care worker cadres is mixed, however, with state policy-makers slightly more knowledgeable than local officials. 
Nearly all policy-makers support task shifting to PHCs due to the structural barriers women face in accessing timely PE/E care at secondary or tertiary facilities. According to policy-makers, a national effort to revitalize the PHC system has begun, for ensuring at least one fully functional PHC facility per ward at all times, including 24 hour running water and electricity, with sufficient personnel. Stock outs in essential maternal health commodities such as $\mathrm{MgSO}_{4}$, calcium gluconate, and anti-hypertensive drugs were reduced, with the proportion of health facilities with $\mathrm{MgSO}_{4}$ stock outs falling from 70 percent at baseline to 21 percent at endline, a major advance in ensuring access to prompt EmOC, especially at PHC facilities, and increasing use of under-utilized life-saving maternal and child health commodities (WHO 2011, Tukur 2009). Linking health facilities to the UNFPA supply chain, along with training logistics managers, may have contributed to this improvement. The project also acknowledges the contribution of Saving Mothers Giving Life and the Global Health Supplies Chain projects for their collaborations to this feat in Cross River and Ebonyi. This collaboration underscores the call for partnership and support assertion that a multi-sectoral action is required to strengthen commodity supply chain for maternal health (Juma et al. 2018).

Despite the success in building the capacities of lower cadre health care providers to detect and manage $\mathrm{PE} / \mathrm{E}$, along with immediate improvements in supply chain processes, inconsistent and shifting funding will continue to negatively affect commodity supply and procurement procedures for essential tools and commodities, impeding the ability of trained providers to detect and manage PE/E in particular, and provide quality ANC, intrapartum care, and PNC services in general. These types of sustainability concerns have been emphasized elsewhere (Rawlins et al. 2018).

Global and national guidelines for managing PE/E are still not routinely communicated to sub-national health officials, contrary to global standards and recommendations (WHO 2014). Where such guidelines are found at sub-national levels, they are not maximally utilized. Future efforts should focus on ensuring global and national guidelines are promptly transmitted and adopted for sub-national use where problems exist.

Improvements were observed at community and policy levels. At endline, community members and policymakers understood that a woman's risk of PE/E and other pregnancy-related complications can be mitigated through early ANC registration and regular attendance. There is accompanying community and political momentum for bolstering improvements in early ANC registration in the states where Ending Eclampsia intervened. One aspect of ANC services that future programmers and researchers should address in low- and middle income countries, including Nigeria, is early ANC registration (Dahiru and Oche 2015, Fagbamigbe and Idemudia 2015, McKenzie, Abdulwahab, Sokpo, Mecaskey 2016).

Pregnant women must register for ANC early, at the latest by the end of their first trimester, so health care providers can apply available guidelines, for their optimal care. If the women in this study each were registered for ANC early, their pregnancies, diagnoses, clinical management, referrals, and maternal and fetal outcomes would have shown greater improvements than these observed in this PHC PE/E model intervention. Only 26 percent of women had registered for ANC before 20 weeks' gestation, and nearly half of women were already hypertensive at their first ANC visit, and three quarters of those with severe preeclampsia. This situation provides little time for meaningful interventions to save lives.

Kogi was the only state in which IR on additional interventions was not conducted (women's group study and testing the feasibility of CHEW HDP diagnosis and management); in Cross River, women's group leaders were trained in PE/E health education for their groups, while in Ebonyi PHC providers received supplemental training on diagnosing and managing HDP, including referral, using aldomet. Future programs should focus on re-training providers and women's group leaders, and scaling up these approaches, as tested in Cross River and Ebonyi. These two interventions, detailed in separate reports, are promising and capable of changing maternal and child health service delivery, if properly employed. 
There seem to be inter-regional differences in community and survivor perceptions of roles of religious and TBAs in shaping pregnancy care, including ANC attendance and interpretation of danger signs and symptoms. In the southern states (Cross River and Ebonyi), women reported the influence of TBAs on their health care-seeking behaviors. In the northern state (Kogi), religious leaders also wield influence. As a consequence, this study shows mixed or simultaneous use of traditional and health facility-based services. In future endeavors, working more closely with both religious leaders and TBAs would make programmatic sense.

\section{Limitations}

One limitation of these data are the unequal sample sizes from ANC observations at baseline and endline, but triangulation among different data sources and types render our study findings robust. Provider industrial actions (i.e. strikes) and absenteeism resulted in barriers to effective regular mentoring of health facilities and consistent ANC visits for pregnant women, and posing challenges to monitoring the women enrolled in the study. Besides Cross River, the project did not implement community interventions to raise awareness of PE/E and improve ANC, and this may have contributed to variations in women's knowledge of pre-eclampsia and other pregnancy complications in the other two states. Provider re-deployment, sometimes to facilities beyond intervention sites, was also a challenge. Newly deployed health workers were included in subsequent refresher training, to improve their skills in PE/E detection and management, however. Conflicting training schedules with other implementing partners resulted in fewer health care providers attending updates as planned, but the project tried to accommodate this through cascading training and mentoring visits in conjunction with state MoHs.

\section{Conclusion}

There is consistent and strong support from policy-makers to scale up task shifting of $\mathrm{MgSO}_{4}$ loading dose administration and referral to higher facilities. This favorable policy environment is substantiated by our evaluation of PHC workers' proven capacities to detect, treat, and manage hypertension and PE/E through administration of $\mathrm{MgSO}_{4}$ loading doses and referrals. Facility capacities for detecting, treating, and managing PE/E improved, though variable and shifting funding streams affect PE/E supply chains and procurement procedures. Inconsistent commodity supply negatively affects the sustainability of PE/E detection and treatment, as well as the technical quality of ANC, maternity care, and PNC in facilities.

\section{Recommendations}

- Streamline state procurement and enhance links to central distribution channels to ensure PHC supplies of $\mathrm{MgSO}_{4}$ and anti-hypertensive drugs;

- State plans should incorporate the PHC model including mentoring and supportive supervision for PHC providers' detection and management of HDP, including PE/E;

- Support providers through mentoring efforts and supportive supervision for HDP detection and management, including $\mathrm{PE} / \mathrm{E}$, and improved patient and provider interactions and quality of care; and

- Increase community awareness and engagement, encourage early ANC, and improve health-seeking behavior for pregnancy complications, especially HDP. 


\section{References}

Dahiru, T. and O.M. Oche. 2015. Determinants of antenatal care, institutional delivery and postnatal care services utilization in Nigeria. Pan African Medical Journal 21: 1-17. https://doi.org/10.11604/pamj.2015.21.321.6527

Danmusa, S., F. Coeytaux, J. Potts, E. Wells. 2016. Scale-up of magnesium sulfate for treatment of preeclampsia and eclampsia in Nigeria. International Journal of Gynecology and Obstetrics 134(3): 233236. https://doi.org/10.1016/j.ijgo.2016.06.001

Fagbamigbe, A.F. and E.S. Idemudia. 2015. Assessment of quality of antenatal care services in Nigeria: Evidence from a population-based survey. Reproductive Health 12(1), 1-9. https://doi.org/10.1186/s12978-015-0081-0

Federal Ministry of Health of Nigeria. 2014. Task-Shifting and Task-Sharing Policy for Essential Health Care Services in Nigeria.

Juma, P.A., C. Mapa-Tassou, S.F. Mohamed, B.L. Matanje Mwagomba, C. Ndinda, M. Oluwasanu... C. Kyobutungi. 2018. Multi-sectoral action in non-communicable disease prevention policy development in five African countries. BMC Public Health 18(suppl 1). https://doi.org/10.1186/s12889-018-5826-6

Khandekar, M.S., J.Y. Patil, S.S. Pawar, A.V. Rajgure, S.S. Suryavanshi. 2011. Structural and bulk magnetic properties of Ni-Co-Zn ferrites. AIP Conference Proceedings 1349(A): 1205-1206. https://doi.org/10.1063/1.3606298

Kim, H.Y. 2017. Statistical notes for clinical researchers: Chi-squared test and Fisher's exact test. Restorative Dentistry and Endodontics.

McKenzie, A., A. Abdulwahab, E. Sokpo, J.W. Mecaskey. 2016. Creating the foundation for health system resilience in Northern Nigeria. Health Systems and Reform 2(4): 357-366.

https://doi.org/10.1080/23288604.2016.1242453

Oguntunde, O., Z. Charyeva, M. Cannon, W. Sambisa, N. Orobaton, I.A. Kabo... H. Sadauki. 2015. Factors influencing the use of magnesium sulphate in pre-eclampsia/eclampsia management in health facilities in Northern Nigeria: A mixed methods study. BMC Pregnancy and Childbirth 15(1): 1-8. https://doi.org/10.1186/s12884-015-0554-8

Okusanya, B.O., O.T. Oladapo, Q. Long, P. Lumbiganon, G. Carroli, Z. Qureshi... A.M. Gülmezoglu. 2016. Clinical pharmacokinetic properties of magnesium sulphate in women with pre-eclampsia and eclampsia. BJOG: An International Journal of Obstetrics and Gynaecology 123(3): 356-366. https://doi.org/10.1111/1471-0528.13753

Oladapo, O., O. Adetoro, B. Ekele, C. Chama, S. Etuk, A. Aboyeji... A. Gülmezoglu. 2015. When getting there is not enough: a nationwide cross-sectional study of 998 maternal deaths and 1451 nearmisses in public tertiary hospitals in a low-income country. BJOG: An International Journal of Obstetrics and Gynaecology. https://doi.org/10.1111/1471-0528.13450

Rawlins, B., M. Plotkin, J.P. Rakotovao, A. Getachew, M. Vaz, J. Ricca...P. Gomez. 2018. Screening and management of pre- eclampsia and eclampsia in antenatal and labor and delivery services : Findings from cross-sectional observation studies in six sub-Saharan African countries, 1-11. 
Singh, S., E. Ahmed, S. Egondu, N. Ikechukwu. 2014. Hypertensive disorders in pregnancy among pregnant women in a Nigerian Teaching Hospital. Nigerian Medical Journal 55(5): 384. https://doi.org/10.4103/0300-1652.140377

World Health Organization. 2011. WHO recommendations for Prevention and treatment of pre-eclampsia and eclampsia. Geneva.

Townsend, R., P.O. Brien, A. Khalil. 2016. Current best practice in the management of hypertensive disorders in pregnancy. Integrated Blood Pressure Control 9(1): 79-94. https://doi.org/10.2147/IBPC.S77344

Tukur, J. 2009. The use of magnesium sulphate for the treatment of severe pre-eclampsia and eclampsia. Annals of African Medicine 8(2): 76-80. https://doi.org/10.4103/1596-3519.56232

World Health Organization. 2014. WHO recommendations for prevention and treatment of pre-eclampsia and eclampsia: implications and actions. https://apps.who.int/iris/handle/10665/119627

World Health Organization. 2018. Maternal Mortality.

World Health Organization, UNICEF, UNFPA, World Bank Group, United Nations Population Division. 2015. Trends in maternal mortality: 1990 to 2015: estimates by WHO, UNICEF, UNFPA, The World Bank and the United Nations Population Division. 